February 1999 • NREL/SR-620-25868

\title{
Non-Economic Determinants of Energy Use in Rural Areas of South Africa
}

Wendy Annecke

Energy and Development Research Centre, University of Cape Town South Africa

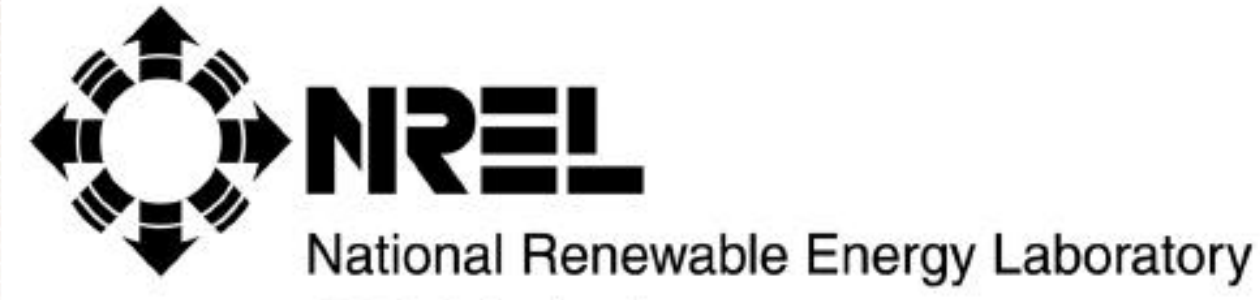

1617 Cole Boulevard

Golden, Colorado 80401-3393

NREL is a U.S. Department of Energy Laboratory

Operated by Midwest Research Institute $\cdot$ Battelle $\bullet$ Bechtel 


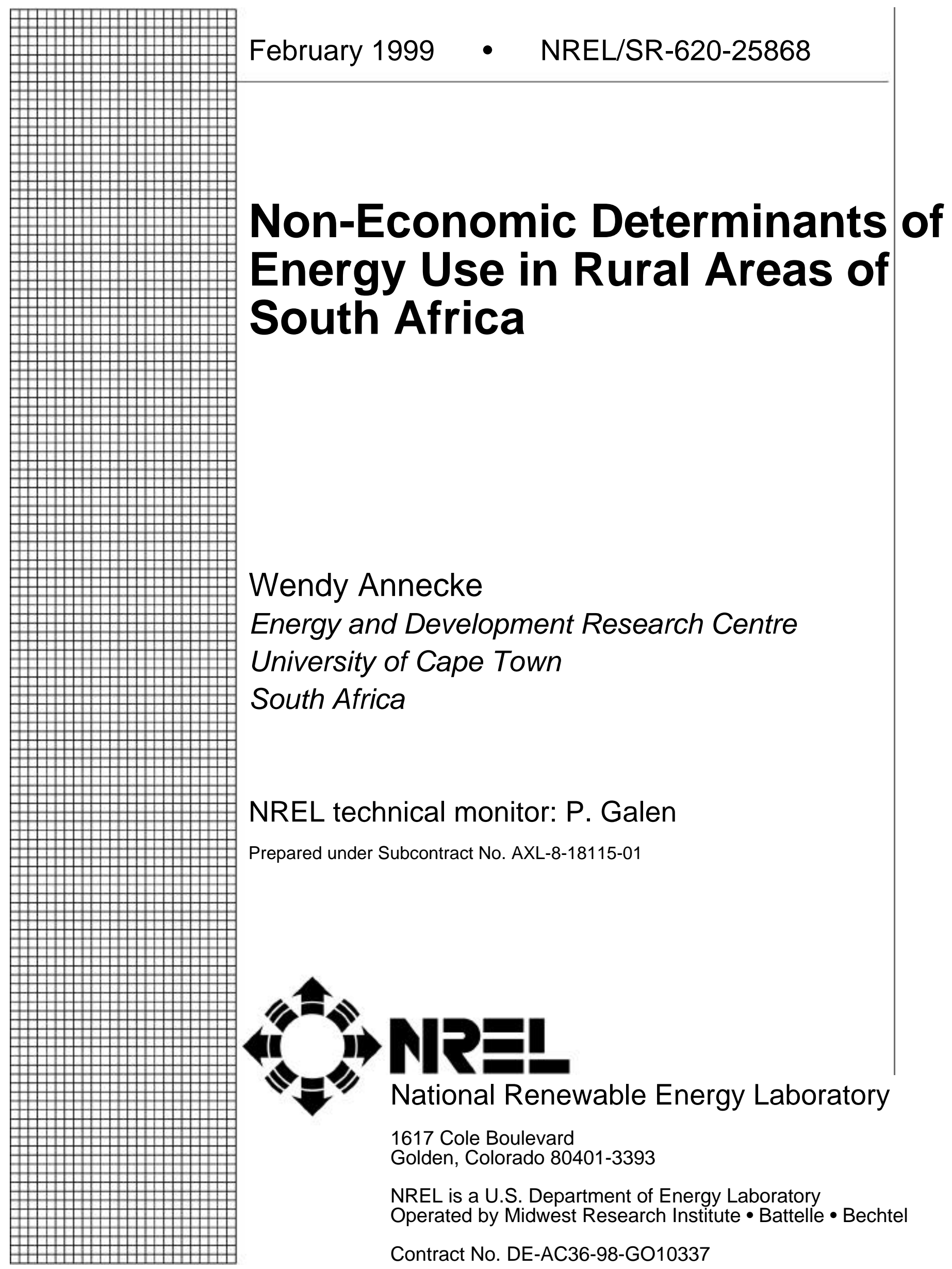




\section{NOTICE}

This report was prepared as an account of work sponsored by an agency of the United States government. Neither the United States government nor any agency thereof, nor any of their employees, makes any warranty, express or implied, or assumes any legal liability or responsibility for the accuracy, completeness, or usefulness of any information, apparatus, product, or process disclosed, or represents that its use would not infringe privately owned rights. Reference herein to any specific commercial product, process, or service by trade name, trademark, manufacturer, or otherwise does not necessarily constitute or imply its endorsement, recommendation, or favoring by the United States government or any agency thereof. The views and opinions of authors expressed herein do not necessarily state or reflect those of the United States government or any agency thereof.

Available to DOE and DOE contractors from:

Office of Scientific and Technical Information (OSTI)

P.O. Box 62

Oak Ridge, TN 37831

Prices available by calling (423) 576-8401

Available to the public from:

National Technical Information Service (NTIS)

U.S. Department of Commerce

5285 Port Royal Road

Springfield, VA 22161

(703) $605-6000$ or (800) 553-6847

or

DOE Information Bridge

http://www.doe.gov/bridge/home.html

This publication received minimal editorial review at NREL

Printed on paper containing at least $50 \%$ wastepaper, including $20 \%$ postconsumer waste 


\section{Contents}

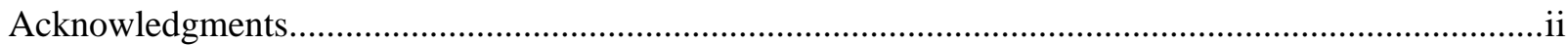

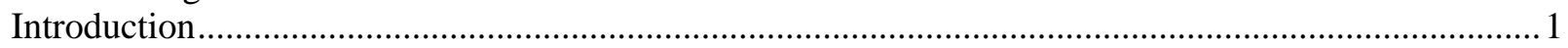

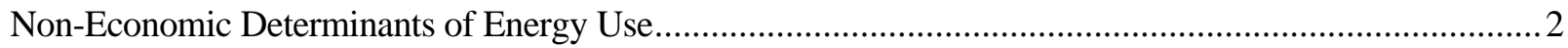

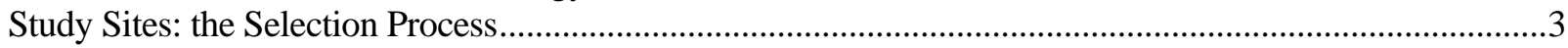

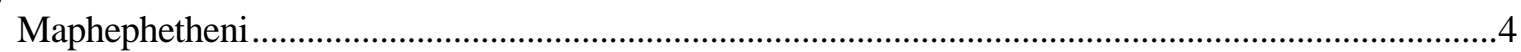

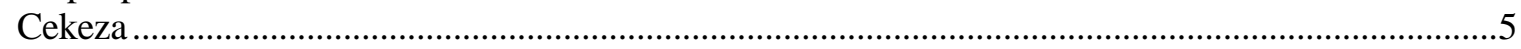

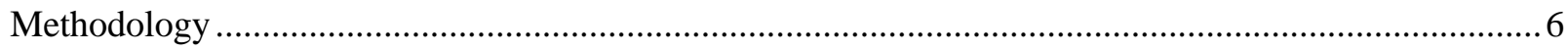

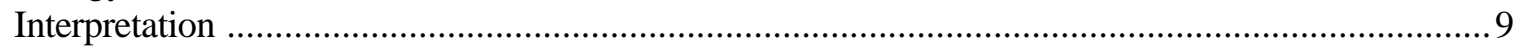

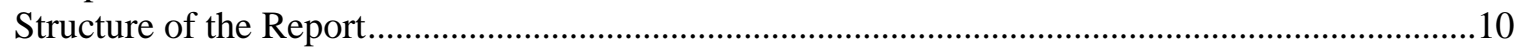

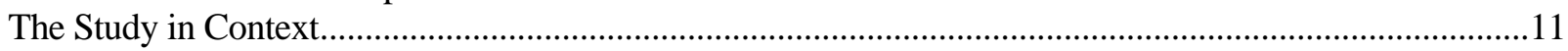

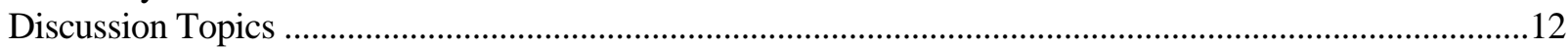

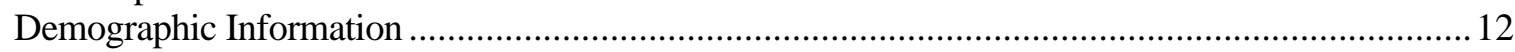

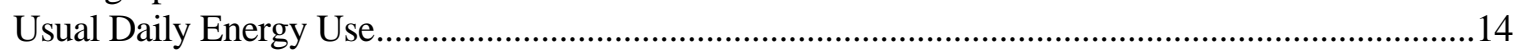

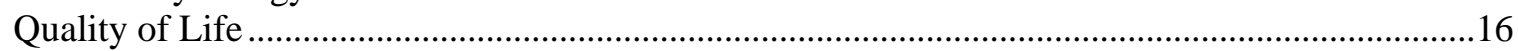

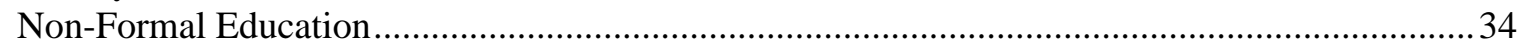

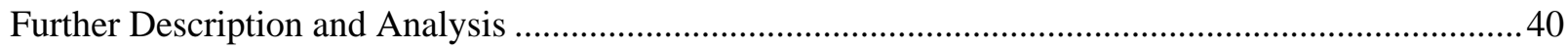

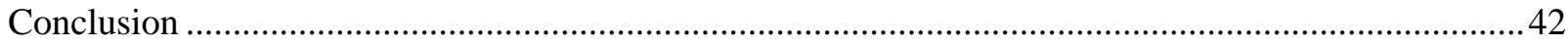

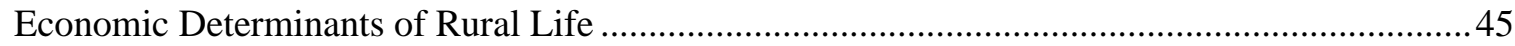

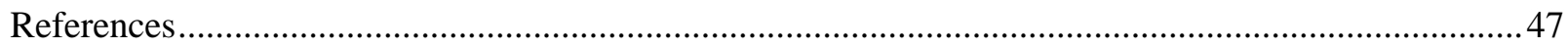

\section{Tables}

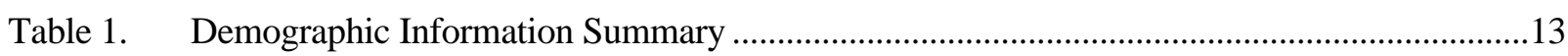




\section{Acknowledgements}

Acknowledgement and thanks to Maria Mbuli and Nonhlanhla Mkhize for their thoughtful work and comments on this report.

I would also like to thank the following contributors to this study:

\section{Eskom}

Michael Mfeka: Head of Electrification Lawrence Hlongwe

\section{Maphephetheni \\ Inkosi Gwala \\ Dorcas Gwala \\ Thulani Gwala \\ Mr. Zwane, Principal Myeka High School \\ Will Cawood, Solar Engineering Services}

\section{Steering Committee Meeting}

Will Cawood

Theo Kheswa (KFC)

Bheka Gwala

Dorcas Gwala

Stella Gwala

Fisani Dlamuka

\section{Cekeza's Women's Group}

Angeline Dlamini

Catherine Langa

Mzamani. Langa

Elizabeth Mkeuze

Elsie Dlamini

Caroline Dlamini

Nontsikelelo Dlamini

Nesta Dlamini

Bongwe Ngwbo

Nonhlanhla Skhosana

Dora Myandu

Bakhethune Shezi

Mlotswhana Dlamnka

Ntomb Kayise

Zibongile Mzimela

\section{Cekeza Second Group}

Dladla Phumzile

Xaki Nonkululeko

Sontsele Ntombelanga

Kheswa Nokuthula

Sikhosana Thembekile

Dlamini Makhosazana

Dlamini Philisiwe

Skhosana Thokozani

Dlanlini Lindeni

Shozi Vuyiswa 


\title{
Non-Economic Determinants of Energy Use in Rural South Africa
}

\author{
By \\ Wendy Annecke \\ Energy and Development Research Centre \\ University of Cape Town \\ South Africa
}

\section{Introduction}

The current electrification program will be completed in the year 2000. This leaves very little time to prepare an electrification plan for years beyond 2000. It is clear that future electrification efforts will focus more on rural, less densely populated areas. To bring at least basic electric services to the rural population, the South African government has recognized that use of off-grid technologies may be a necessary step. Consequently, it is important that appropriate strategy and policy be implemented after the current electrification program is completed.

This project will begin to determine the forces and dimensions in rural energy-use patterns and begin to address policy and implementation needs for the future. This entails:

- Forecasting the social and economic benefits that electrification is assumed to deliver regarding education and women's lives

- Assessing negative perceptions of users, which have been established through the slow uptake of electricity

- Making recommendations as to how these perceptions could be addressed in policy development and in the continuing electrification program

- Making recommendations to policy makers on how to support and make optimal use of current energy-use practices where these are socio-economically sound

- Identifying misinformation and wasteful practices

- Other recommendations, which will significantly improve the success of the rural electrification program in a socio-economically sound manner, as identified in the course of the work

For scoping purposes, this study will define broad parameters and potentially interesting areas for further in-depth investigation and policy recommendation. A robust, longitudinal, follow-up study has been approved by Eskom and is due to start towards the end of 1998.

Thus far, research has established that multiple fuels are used prevalently in low-income households in South Africa even after they have been electrified. While economic factors are surely important to such a choice, earlier research conducted in South Africa and elsewhere suggests that non-economic factors also play an important role_-factors like lifestyle preferences, habit, and decision-making powers.

These factors occur within a context of economic hardship and rural deprivation; policy makers and implementers must understand their weight to maximize the benefits of rural electrification projects. Some of the non-economic determinants for urban, low-income households are beginning to be 
understood-for example, that electrical appliances must be purchased before an outlet is of benefit. Such information has not been gathered in rural areas, however. ${ }^{1}$

Understanding the non-economic determinants of off-grid, renewable technologies use depends, in part, on understanding how household choices are made in the rural setting. Thus, the purpose of this project is to begin acquiring the knowledge and understanding necessary to advance policy discussion regarding electrification and effective integration of renewable, off-grid technologies into a new electrification strategy and program.

This preparatory study was conducted at two rural sites where multiple fuel use is known to be prevalent (qualitative analysis of this has not been done). The first, Maphephetheni, was a site where solar home systems had been installed over the last 3 years. Wood, paraffin, and gas were still being used for thermal applications. Eskom electrified the second, Cekeza, in late 1997. Wood was still of primary importance for thermal applications, although some paraffin and gas was also used, and electric irons, kettles, and stoves were beginning to be purchased. Although small-scale, intensive studies do not yield results that can be generalized, these sites do provide insight into particular energy-use patterns and yield information that may be used to great benefit in the follow-up study.

The study attempted to initially assess rural energy users' attitudes about different energy carriers and how these might meet their needs. Participatory methods were used to derive insight at the micro level into forces that determine energy-use patterns and people's perception of these. The study particularly noted changes in perception about the improved quality of life for women, improved nonformal education of rural people, and improvements to livelihood strategies resulting from the availability of grid- and non-grid electricity. Alternative delivery approaches to increase such changes in perception are considered in the conclusion of the report.

\section{Non-Economic Determinants of Energy Use}

Non-economic determinants of energy use include attitudinal, behavioral, and cultural practices. These practices, although frequently subjective and personal, have their bases in shared material conditions and experiences. These individual, subjective, and collective determinants are what this study seeks to explore and understand.

We explored non-economic determinants through two specific aspects of daily practices—both of which involve energy use and reflect attitudinal, behavioral, and cultural habits. These were:

- Energy-use practices that impact quality of life for women

- Energy use in non-formal education

Important, non-economic determinants for energy use-lifestyle, convenience, habits, constraints, customs, preferences, priorities, control over and access to resources-were explored in two crucial areas: improving the lives of poor, black women and extending knowledge, information, and education to the disadvantaged and marginalized.

Two hypotheses were made. The first is that electricity will lead to a decrease in drudgery for women. Benefits will include time for income generation or leisure activities, leading to an improvement in

\footnotetext{
${ }^{1}$ The national research project done by EDRC and others, which has probed the social determinants of energy use in four metropolitan areas over the past three years (1995-1997), has provided some useful insights into urban electricity use: the reasons for low uptake and evidence of extensive and continuing fuel use.
} 
health and safety and an improvement in self-esteem. If so, then changing energy-use patterns will reflect these changing conditions.

The second hypothesis was that, by providing electricity to rural areas, lighting and electricity will be used for reading, computers, radios, and televisions in ways that will lead to an improved general knowledge-facilitating participation in the modern world. If this holds true, then changing energyuse patterns will substantiate the shifts. Accordingly, questions and a research method were designed to explore these hypotheses.

\section{Study Sites: the Selection Process}

The Statement of Work required that this scoping study be done at just one site, where multiple fuel use was prevalent. It did not specify whether the site should be electrified, be on or off grid, or be in any specific province.

I had conducted previous fieldwork in urban and rural areas in KwaZulu-Natal and had the necessary links and networks to go into these rural areas with comparative ease. There was not sufficient time to become acquainted with another area and make the connections necessary to conduct a successful study, so the selection of province was relatively simple.

KwaZulu-Natal is not an easy province in which to work. It has a history of violent conflict between political parties, factions, and warlords. Recently, this has re-surfaced and escalated to an alarming degree in Richmond in the midlands, but also up and down the coast. Conflicts did not disturb the study, however.

KwaZulu-Natal offers considerable challenge to any electrification program. Its topography varies from steep gorges, to undulating hills, to narrow coastal plains; settlements are widely scattered. It has the largest rural population of all provinces and often has complicated relations between the traditional tribal authorities and the government. Any one study in KwaZulu-Natal may offer a multitude of lessons-so although difficult it is also ideal.

Having settled the question of the province, we sought two co-workers to assist with sites selection. A Zulu-speaking companion and experienced fieldworker, Maria Mbuli, was engaged to assist with the work. A younger trainee, Nonhlanhla Mkhize, was also appointed to accompany us.

Since the purpose of the study was to contribute to strategy and policy to be implemented after the conclusion of the current electrification program, the first choice was a site in KwaZulu-Natal where households had been newly connected to the grid. Here the immediate impact would be still noticeable and changes over time could be tracked through the follow-up study. Cekeza, a site suggested by Michael Mfeka, head of electrification for Shelley Beach, appeared to be most suitable.

Grid and off-grid electrification sites are usually mutually exclusive in South Africa. There are no known sites that are on grid and off grid simultaneously. Prior to the site visit to the on-grid Cekeza site, an opportunity arose to study an off-grid project as well. A comparative study at two sites-one on grid and the other off grid-was obviously an advantage. The off-grid site was Maphephetheni. This is how it happened that two sites were studied instead of one. 


\section{Maphephetheni}

Solar and PV projects for low-income households are still in their infancy in South Africa ${ }^{2}$. The solar home systems project at Maphephetheni is one of few reportedly successful off-grid pilot projects that have been in operation for more than 3 years. Here Will Cawood, of Solar Engineering Services, has installed more than 50 solar home systems as well as a hybrid PV and gas system for the computer room at Myeka High School. He has done this over the 3 years with the help of a three-person, parttime team. We were keen to learn about the progress of the project and its impact, compared with the grid project's progress. We made arrangements with Cawood to visit the site with him on August 12, 1998.

Maphephetheni is situated in the Valley of a Thousand Hills, some $80 \mathrm{kms}$ west of Durban. The terrain is mountainous, bordered by the Umgeni River and Inanda Dam to the south. From the hot and dusty thickets down to the huge blue waters of the dam, the outlook is rugged and beautiful. Alien vegetation covers much of the land, sucking up what water there is and leaving little grazing except for goats.

Some 20,000 people live at Maphephetheni in various degrees of poverty and subsistence. A few work in Durban and commute every day; many rely on pensions and casual labor when this can be found. Homesteads consist of clusters of mud and thatch rondavels situated some distance from each other across the hills and in the valleys. Footpaths provide the primary access to homesteads. Each homestead has a piece of land, some of it arable, and most people keep small livestock (chickens and goats). Shared communal gardens are situated close to the river.

Vehicle access along route roads is difficult during the summer rainy season when badly eroded roads become impassable. For most of the year, hardy local taxis and buses provide daily transport.

We accompanied Cawood to the courthouse at Maphephetheni. As is correct procedure, we met with the Inkosi, Mr. Gwala, and introduced ourselves. He is a young, progressive chief who oversees the region and has been largely credited with establishing peace since his father was killed. His views on electrification are clear. He has stated on several occasions that one of his ambitions is "to see electric lights shining forth from every homestead in his community" (Cawood 1997) —and he would rather that these were powered by the grid.

The eastern part of Maphephetheni falls under the jurisdiction of Durban Electricity; the rest is currently under jurisdiction of Pinetown Eskom. Before the solar home system project started, Durban Electricity and Pinetown Eskom indicated in writing that they had no plans to provide grid electricity to the area for the next 5 years. Nonetheless, limited electrification has since taken place in an adjacent area, causing irritation and frustration to the Inkosi and his people.

The Department of Minerals and Energy provided the funding for the courthouse's solar system. The courthouse's sparsely furnished row of three offices forms the center of the village. In addition, the village center includes a newly completed and wired clinic which was still unused, a new building for community meetings, a 2-year-old Telkom card phone (which has not worked for the past year), a lively shop, and a bore-hole with the accompanying hub of activity. To the east down the dirt road is Myeka High School, headed by enterprising principal Mr. Zwane. The school is unique in the area

\footnotetext{
${ }^{2}$ A major scheme involving the Department of Minerals and Energy and the Bavarian government is being planned and implemented at Folovodwe in the Northern Province. It is hoped that this report may contribute to such planning.
} 
because it has a computer room with 20 computers donated by IBM, powered by a hybrid solar and gas system.

From the courthouse we proceeded to a building where a mobile clinic was in progress and from there to Dorcas Gwala's homestead. Dorcas is the chief sales person for the solar home systems. A meeting of the full solar team, which includes Theo Kheswa, a representative from the KwaZulu Finance Corporation, is held at her house about once a month. We sat in on the meeting where new sales, installations, new applications for loans, and problems with finance and systems were discussed.

The first sales were a result of demonstrations by Cawood, but Dorcas's advertising and word of mouth recommendations are responsible for a continuation of sales. Typically, a customer buys a solar home system consisting of three 9-watt compact fluorescent lights powered by a 53-watt power PV module, with overnight storage via a 105AH semi-sealed lead acid battery, and a 10A charge regulator. Wall-mounted switches, a television plug, and installation are included in the cost. In October 1997 this cost 2,987 South African Rand (R2,987) (Cawood 1997). Buyers also receive ongoing attention and maintenance from Cawood and his team.

By the end of the solar home systems meeting, so many interesting questions had arisen that Maria, Nonhlanhla, and I had conferred and decided that at least part of our study should be at Maphephetheni. It was clear that the differences in experience between the households with solar home systems and those with grid connections would make an interesting comparative study.

At the end of the meeting I was given an opportunity to explain our presence at the meeting and requested permission to do some of our work in the area. Cawood immediately liked the idea, and the other members agreed. Taking advantage of the Inkosi's availability that day (he is often away) we stopped at the courthouse on the way back to discuss the matter with him and gained his consent.

\section{Cekeza}

The following day, August 13, 1998, Maria, Nonhlanhla, and I went down to the Eskom office at Shelley Beach, about 2 hours south of Durban, where we met with Head of Electrification Michael Mfeka. Mfeka had arranged for Mr. Lawrence Hlongu to accompany us to Cekeza to assess its suitability.

Cekeza is located in the Izingolweni magisterial district. It lies towards the former Transkei, approximately $20 \mathrm{kms}$ off the main tar road to Harding in southwestern KwaZulu-Natal. The terrain is rough and beautiful; not as stark or dry as Mapthephetheni but greener, with undulant grassed hills and steep valleys down to the Umzimkulu river where most of the residents go to fetch their water and do their washing. The less harsh aspect belies the depth of endemic poverty.

Although less harsh in landscape, the people at Cekeza are worse off than those at Maphephetheni. The area is more isolated and is situated at a greater distance from labor markets. The community is very poor, depending heavily on state pensions, subsistence farming, and irregular remittances from migrant workers. There is scant opportunity for commuting or contract work on the surrounding (white-owned) farms and forests.

Homesteads are widely spread along the crests of hills, many accessible only along footpaths. Most are made up of clusters of mud-rondavels with thatched roofs, although square, flat-roofed buildings built in cement block have begun to appear. Each homestead has land allocated to it and some are able to use this for subsistence farming; in addition, many homesteads keep livestock. There is no clear center of the village, although the rather dilapidated courthouse serves as a meeting point as 
does the general store (Phola Phola), which is close to the high school but several kilometres from the courthouse. There is another store in the adjacent area called Santombe.

The area lacks basic facilities in the same way as Maphephetheni does: it does not have water, its own clinic, or sufficient schools. The water that people use comes from the river-the few water tanks are only full in summer. The only secondary school, Ecekeza High School, serves a vast district.

The recent grading of dirt roads, the building of a creche, and electrification have been welcomed as signs that development is coming although many of the roads are still impassable in the rainy season. Transport is by taxi or what are known in South Africa as "bakkies."

Eskom electrified Cekeza late in 1997, after years of indecision because of the cost of providing infrastructure to such a sparsely populated and hilly area, stretching up to 20 kilometers from one end to the other. The chief of the area, Inkosi Dlamini, first applied to Eskom for electricity in 1995. The adjacent area, Santombe, was electrified in 1996. Eskom overcame a set of problems and electrified parts of Cekeza in 1997. The Inkosi's homestead, which is some distance from the grid, was electrified, but many homesteads under his jurisdiction were not. This has led to great disappointment and dissatisfaction, as is reflected in the interviews.

On arrival at Cekeza we went straight to the Ecekeza High School where we greeted the headmaster and explained our business. Inkosi Dlamini teaches at the school, so we were able to introduce ourselves, describe our work, and obtain permission to work in the area. The principal also called together a group of women teachers so that we could discuss the study and negotiate with them, too. We agreed to be back on Monday, August 24 for the week, although there was some concern expressed that Tuesday, August 25 was payday and no one would be available. It would appear that the old habit of all teachers going into town for the day on payday is still practiced. As it happened, the study was done in the following week.

\section{Methodology}

This scoping study offered a unique opportunity to test the design for a new area of study in energy. The objective of the study was to begin to distinguish non-economic determinants of household energy use in rural areas through two specific routes of inquiry: how electrification impacts women's quality of life and is reflected in their energy-use patterns, and how electrification impacts non-formal education and the changes in energy-use patterns this may induce.

Quality of life is difficult to define, so we gathered both quantitative and qualitative evaluations of

daily life from women. The literature (Davis 1995) describes the impact of electrification on women's quality of life in terms of increased appliance acquisition and improved income via small or micro enterprises. While it was considered important to test these components, quality of life also incorporates subjective judgements about leisure, fulfillment of aspirations, and the experience of hardships and likely improvements - so opinions of these were also sought. Women were asked about their daily lives in a number of ways, including their perceptions of past and current energy-use patterns, prospects for the future, and the role of electricity in their future lives.

Non-formal learning is perhaps even more difficult to quantify than quality of life. Non-formal learning happens through the daily socialization processes, including such activities as reading, listening, watching, discussing, and selecting (consciously or unconsciously) ways of making meaning of and being in the world. Rather than attacking the deeper philosophical question, this first stage in the project tried gain understanding on how participants perceive their own learning, when and how the learning takes place, and account for uses of lighting, availability, and choice of reading 
material and audio-visual programs.

Attitudes and behavioral and cultural practices that underpin every day living are best explored by using techniques such as story telling, scenario building, games, and /or role play, which can explore below the surface meaning. These types of interaction are more suitable than formal questionnaires, which may sound like an interrogation and evoke monosyllabic or over-simplified responses. For the former techniques to be meaningful there should be some degree of trust built up between the participants and the facilitator. Group meetings should be arranged to suit the rhythms of the community concerned and a number of different groups should be run over several weeks. Research should be supported by participant observation and full secondary demographic information and literature on the community and area.

A quick, sharply focused scoping study such as this one cannot employ the range of participatory techniques desirable in such a wide-ranging study as is usually used by EDRC researchers doing qualitative analysis. Such processes require far more time than was available for this study both in terms of number of days spent in the field and time available to arrange meetings and run them satisfactorily, and in terms of establishing some sort of trust with prospective participants.

It is not necessarily easy to arrange group meetings, even in small, rural communities like Maphephetheni and Cekeza where the rains have not yet arrived and many people are not employed. Working in tribal areas in most of South Africa requires the permission of the Inkosi. Visitors to the area should introduce themselves to the Inkosi and explain their business before proceeding. This is correct and courteous procedure, without which one is unlikely to receive the co-operation of the residents.

In both Maphephetheni and Cekeza, we were fortunate to arrive on a day when we were able to meet the Inkosi and obtain permission to do our study. Consultation with the Inkosi then ensues on how the study should be done. Obtaining permission to hold a group meeting, deciding with him whom to invite, and agreeing to a venue and a time can take several hours. Then prospective participants have to be visited in their homes and their participation secured. If the designated time and day coincide with a visit from the mobile clinic, pension pay-out day, teachers' payday, or any such event that may prevent two or more prospective participants from being in the group, then it is back to the Inkosi to consult on whom to invite instead.

Methodology for this study, since time was of the essence, was designed to suit the purposes of the study in the context of rural KwaZulu-Natal. What we wanted was to understand the similarities and differences that determine lifestyle choices within households and consequently affect energy-use patterns. ${ }^{3}$ What we needed was a technique that would provide the opportunity to ask relatively personal questions as well as more general ones within a controlled length of time.

Questionnaires, as opposed to group meetings, require only the permission of the Inkosi, agreement of the participants, and legwork of the researcher. But static questionnaires requiring monosyllabic responses (known to be the domain and method of quantitative research) were clearly not appropriate. An interview with open-ended questions, requiring the engagement of both participants, can become an in-depth conversation and provide the nuanced responses we were seeking. Such interviews can be done with individuals or households at their convenience and in the privacy of their homes.

\footnotetext{
${ }^{3}$ Households, of course, are no longer thought of as consisting of a nuclear family with a male breadwinner, mother, and two children, but recognized to take many forms and shapes including, in these rural areas, pensioners as the sole recipients of regular income in the form of a state grant, etc.
} 
Since group discussions are not the ideal format for acquiring detailed facts like age and income, we decided to use structured conversations to get details and to elicit some of the similarities and differences within households that might influence energy-use patterns. The interviews would then be enriched and supported by about three group discussions arranged at each site. In addition, staying with households in the area would allow us a sort of reality check - to assess whether things happened the way they were reported to. Thus the methodology included a combination of structured interviews or conversations, focus-group discussions, and participant observation.

The structured interview was developed at EDRC, piloted with two fieldworkers in KwaZulu-Natal, and adjusted accordingly. It was divided into roughly three sections. The first consisted of a brief bibliographic section detailing the age, occupation, and income of each member of the household. The second was intended to assess the quality of life of the primary caregiver (woman) through a "contentment index." The index would allow us to asses women's perceptions of the best and worst parts of their lives, how electricity had affected their lives, how the future looked for their children, and what energy-use patterns may be implicit in their lifestyles and choices (if any). The third section was intended to probe the role of electricity in non-formal education, the function of lighting for extension classes and media (print, radio, and television), and what respondents believed they learned from these.

Group discussions were intended to flesh out information from the interviews and, through the process and group dynamics, offer different insight into the many facets of rural life and energy use that interested us. Three such groups were decided on:

1. A women-only group. Because the traditional patriarchal and rural culture insists that women should be subservient and silent, a women-only group was intended to give women the space and opportunity to voice their opinions and tell their stories about the quality of their lives.

2. A mixed group of adult men and women. It was intended that this group would briefly discuss the impact that electricity had on the community and spend some time on media, opportunities, and access to non-formal education.

3. A group of secondary school children. As the adults of the future, we hoped this group would provide insight and understanding into the next generations' aspirations for lifestyle and education and the role of electricity in these.

In general the interviews worked well. At each homestead we introduced ourselves, our research, and invited participation. No homestead refused. However, communities in rural areas throughout South Africa are wary of strangers who arrive, ask numerous questions, make a variety of promises, and disappear. Rural areas are over-visited but not over-resourced, and communities resent receiving no response to their requests or complaints. Thus we tried to convey that we were not making false promises or raising false expectations in the interviews and discussions.

We gave each respondent a small token of appreciation for their time and the invasion of their privacy (250 grams of tea leaves, 500 grams of sugar, powered milk, and cookies) and provided resource material on energy for the local high school. In addition, every effort was made to engender trust since the same areas and people will be visited in the follow-up study. For this reason, we became involved in several tasks that lay outside the parameters of the study to reciprocate some of the good will and information extracted.

We began the group discussions with an icebreaker to introduce ourselves and give the participants an opportunity to ask questions. The participants were interested to know about us: our families, 
partners, education, hobbies, what we thought of rural areas, and why we were there. We answered honestly, and since we had each spent some time living in rural areas without electricity and running water we could identify with the group at some level.

Naturally, we also helped with the domestic chores at the homestead where we were staying in the evenings. Word spread to this effect, so after the first night conversational and an informal atmosphere of mutual trust and respect was less difficult to create. Open-ended questions, role play of difficult situations (discussed later), and invitations to write or draw were used in the groups. Group discussions lasted between 1 and 2-1/2 hours and fruit juice, potato crisps, and biscuits were provided for the participants.

Though more time would have been appropriate, we were able to complete all the interviews and run two of the three groups intended. At each site, 20 household interviews were conducted. Interviews took between 30 to 45 minutes, depending on how forthcoming the respondent was. It took from 20 to 45 minutes to walk along the footpaths from one homestead to another. Then there were the prolonged greetings and explanations, and the idea of meeting as groups still had to be discussed and agreed upon.

At Maphephetheni people were disappointed that we hadn't given them enough warning and were in the area for only a few days. Only six women could participate in the group, and we could not muster a mixed group because of a development forum meeting (many of the men were involved). However a most responsive group of school children gave helpful insights into their ways of learning and their aspirations.

At Cekeza, where people had had due warning of our visit, attendance was enthusiastic: 28 men and women arrived and wanted to discuss both topics. Unfortunately, a school group could not be arranged at Cekeza. Thus the group discussions do not provide equivalent comparative information, but they do provide some useful insights and suggestions, which are incorporated into the report.

In summary, we conducted 40 in-depth, structured interviews: 20 at at Maphephetheni, each one with an owner of a solar home system, and 20 at Cekeza, 17 with householders who had been connected to the grid and three whose homesteads had not been included in the project. Two groups discussions were held at each site. At Maphephetheni discussions were held with a group of women and a group of school children. At Cekeza discussions were held with a group of women and a mixed group of men and women. We conducted interviews and most of the group discussions in Zulu.

Although we attempted to gather both quantitative and qualitative information, we did not attempt in this pilot project to achieve any kind of representative or random sampling. The criteria for participation at both sites was electrification, accessibility (to us on foot), and willingness to participate. The three non-electrified households at Cekeza were included at their own request and provide examples of the bitterness of those who were omitted when the area was electrified.

\section{Interpretation}

To get an idea of women's perception of their own lives, of the hardships and the joys, and perhaps to uncover attitudes and behavioral patterns that may influence resource and energy use, we asked about the hardest parts of the women's lives. Many women included energy, or a lack thereof, as a hardship - primarily in terms of having to collect wood and water. Hardship has many dimensions; many women took the opportunity to discuss the multi-faceted stresses in their lives. 
Several women responded in ways that were initially difficult to interpret. One of these was Mrs. D. She sat straight-backed, legs outstretched, barefoot in the shade of her cooking hut where the conversation took place. As is customary, a low-key fire burned constantly in the fireplace in the center of the hut. Some smoke trailed up towards the highest part in the thatched roof and filtered its way through cracks between the thatch and the center cone- there are no holes to act as chimneys. The rest of the smoke swirled lazily around the lower reaches of the rondavel, adding another thin layer of soot to the smoke-encrusted roof and walls and wafting out to burn the eyes and throat of the visitor.

It was one of the poorer homesteads. Inside the sleeping huts were few worldly goods or ornaments, sleeping mats rather than beds or mattresses, and few clothes or shoes. In the dark, smoky cooking hut there was a rickety table, an assortment of yellowish plates and cups fashionable 20 years ago, bits and pieces of cutlery, two three-legged cooking pots, and a paraffin stove used only in special circumstances such as at night when it has been raining for days on end.

Mrs. D. was quiet for a while after being asked what hardships she experienced in her life. I waited. I assumed that at 54 she must have had numerous hardships. After a while she shook her head and said there was "nothing hard that she could think of." How should an outsider with privilege, education, and material wealth interpret such a response: literally, as an expression of contentment; as lacking aspirations; or as denial?

Mrs. D. was quiet again, and she mused, "Now that there is less violence, now that the children are home and one might get a job, now that I can see them, now there is nothing hard, not really hard, not hard like not knowing if they were alive. Not hard as the hardships of a few years ago." The "nothing" is thus not an absolute but a relative value. Knowing that there is not going to be enough food may be less difficult to manage than not knowing who in the family is dead or alive each morning, but should either be considered a satisfactory condition?

The implications of a similar response (no hardships) in another interview raised a different set of questions. When we asked, "Can you tell me about the hardest parts of your life?" a chill entered the space between us. The response, "there is nothing," invited no discussion. No further comment was offered, no dwelling on the past or improvements possible in the future. Just silence. In this case "nothing" really meant "there is nothing I want to tell you or remember because it is too painful."

Another example of differences in meaning from the same words: we noticed that words such as resources, infrastructure, and development had different emphasis when used by different respondents. When the Inkosi Dlamini used the terms, he was referring to roads, electricity, piped water, and employment opportunities. While these were also important to the women at Maphephetheini, their use of the terms included the availability of clinics, creches, telephones, shops, and supplies. Thus, interpretation is complex and subjective judgements in this regard are made throughout the report.

\section{Structure of the Report}

The body of the report attempts three things. The first is obviously to fulfill the requirements of the Statement of Work by providing insight and understanding into the non-economic determinants of energy use in rural areas with special reference to the role this plays in women's quality of life and the facilitation of non-formal education.

Because this is a scoping study and will form the basis for a follow-up study, the second purpose is to assess the methodology. This includes a critical scrutiny, not only of the responses but also of the 
questions themselves. The usefulness and one purpose of this scoping study became evident when flaws in the questions were revealed. These are noted in the discussion and will be altered in the follow-up study.

Thirdly, in an attempt to provide the reader with some of the authentic experiences and textured lives of the participants in this study, respondents' voices are heard throughout the report in the form of verbatim statements.

This report is organized by themes that came out of interviews and group discussions. Time limitations did not permit full data analysis.

\section{The Study in Context}

The "Role of electricity in the integrated provision of energy in rural areas" project, which has been running at EDRC for the past 3 years, has shown that electricity will have the greatest use where coordinated or parallel development initiatives are taking place. Such infrastructure as roads, telephones, and clinics may affect the quality of life of women, whereas a lively school or shop that sells newspapers and magazines may influence the quality of non-formal education. It is just as well, then, to begin the discussion of the findings with a reminder of the context of the study sites.

The sites were quite similar in many ways; both are rural areas under a tribal chief, with scattered traditional homesteads along crests of steep hills dropping down to rivers. At both sites the Inkosi allocated subsistence-farming land. Many homesteads keep small livestock including cattle. The land at Cekeza appeared to be in a better condition than that at Maphehetheni, so the gardens might have been slightly more productive despite a harsher climate.

Both areas are poor, but Cekeza people are worse off because they are further from employment opportunities and urban trickle-down benefits. There was less crime at Cekeza, with many traditional practices still in place. It is ironic that Maphephetheni, just $80 \mathrm{kms}$ from the city of Durban, should be designated as off-grid territory whereas Cekeza, some $350 \mathrm{kms}$ from the major city, is grid electrified. This has made a significant difference to levels of satisfaction and quality of life assessments in the two areas.

Maphephetheni's water supply comes from rivers, streams, springs, and the dam. Recently the Department of Water and Forestry has put in boreholes with hand-pumps. Although not all of these are working yet, the ones that are make a considerable difference to water supply. Women and children still have to walk to collect water and sometimes queue, but boreholes reduce the distance and danger of contaminated water.

There are two clinic buildings at Maphephetheni, but neither have staff or supplies. A mobile clinic visits the area every 2 weeks and uses one of the buildings. People needing treatment between times have to find the money and transport to get to a hospital in town. There are schools in the area, and Myeka High School, with its new curriculum and solar-powered computers, has a particularly enterprising headmaster. Infrastructure for telephones does exist—solar and standard—but none are working at present.

The village of Inanda has the closest postal service to Maphephetheni, and a daily bus service operates along the main routes into and out of the Valley of a Thousand Hills. All the development initiatives operate independently of one another; if they all functioned together (all the boreholes worked, the clinics were staffed and supplied, telephones worked), they would make a considerable difference to the quality of life in the area. 
Cekeza has seen several development initiatives in the past few years. Reasonable quality dirt roads have been graded along main routes and smaller roads lead off these so that most areas are accessible by vehicle. Footpath routes to and from homesteads are a little shorter than vehicle routes. Electricity has been installed at homesteads and schools, and prepayment cards are available at the village of Santombe, which is about an hour's walk from the courthouse at Cekeza. A creche has been started and there is one phone at the senior school.

However, there are still no telephones at the Inkosi's courthouse, which is dilapidated and in need of repair, no clinic or medical staff, and no boreholes for water. Women and children fetch water from the river. The water tank at the school relies on rain so that at the time of our visit (the end of winter) there was no water and hadn't been for some months. A mobile clinic operates twice a monthanything more urgent has to be treated at Harding or a relatively inaccessible mission hospital some 60 miles away. The nearest post office is at Harding and taxis operate irregularly.

\section{Discussion Topics}

At the beginning of each interview we made the appropriate greetings and explanations and recorded the name of the respondent. Thereafter, we asked questions in three areas-demographics, perception of quality of life, and non-formal education - to obtain information on current and future energy-use patterns.

\section{Demographic Information}

The composition of the household was recorded because the number of people, their ages, and their genders influence energy-use patterns. For example, where there are several children of school going age, the woman of the house is likely to get up early and want a rapid source of heat to boil water and cook to get the children ready for school. A number of non-working adults may get up more slowly and be satisfied with re-lighting a fire to make tea. Interviews revealed that in a few cases the men as well as women took some responsibility for early morning domestic chores.

In Maphephetheni, we interviewed 112 people altogether in the 20 households. Households had from three to nine members, with an average size of 5.6. Nineteen of the 20 households had children at school. Hot water for tea was a priority in the mornings particularly since in some households it is all that children have before they walk long distances to school. Twelve of the 20 households usually used wood for this purpose, seven used paraffin, and one used gas.

\section{Demographic Information Summary}

\begin{tabular}{|l|l|l|}
\hline & Maphephetheni & Cekeza \\
\hline Total no. of people in 20 households & 112 & 128 \\
\hline Household size & $3-9$ & $3-9$ \\
\hline Income per capita & R200 (\$33) & R120 (\$20) \\
\hline Households reliant on state pension & 6 & 12 \\
\hline Households with school goers & 19 & 16 \\
\hline
\end{tabular}

Regarding income, households reported wide-ranging monthly incomes, from none at all to R2000 (\$333) a month, with an average monthly household income of R1100: about R200 (\$33) per capita per month. This figure is significantly below the poverty datum line. Green (1997) reports that there 
were no significant differences in income between the households that bought solar home systems and those that did not.

As is common in South Africa, pensioners, with their small state grants of R490 (\$82) per month, were the mainstay of several households. In the case of Maphephetheni, six of the 20 households relied on a pension. The households in which there were two pensioners were among the better off. Those with employment worked as casual laborers, teachers, street vendors, taxi drivers, and clerks, earning between R100 and R2000 a month.

In Cekeza there were 128 people altogether in the 20 households interviewed. The average number of people per households was very slightly larger than in Maphephetheni: households varied in size from three to nine with an average size of 6.5. Sixteen out of the 20 households had children at school. Again, hot water for tea was a priority in the mornings before children walked to school. Six use electricity for this; others use wood or occasionally paraffin.

Household incomes varied again, this time from no cash income to R2500 (\$400) a month, with an average monthly household income of R786 (\$131) per household or about R120 (\$20) per capita per month. This is really low, and is exacerbated by the fact that the averages are skewed by four of the 20 households that have an income of R1,500-R2,500 (\$250-\$420) per month. Sixteen of the households survive on less than R600 (\$100) per month. For 12 of these 16, their only income is a disability or state pension grant of R490 per month. Five of these pensioners are over 70 years of age. As one put it,

I'm not thinking about the children. I'm thinking about myself that I might die any day because I am strained and there is no one working here.

Because of their low incomes, the people of both villages have limited choices for energy use. But available resources also limit choice. All households would have liked hot water for washing first thing in the morning. But apart from the energy it takes to heat it, the water to heat was not available. Since water is still carried in, very limited water is available for washing. Until this changes, it doesn't matter what energy sources are or are not available. The point is important, because we don't know how households would re-prioritize their energy use if water were available.

Similarly, energy for cooking food in the mornings is a moot point if there is no food. Tea, sometimes from the previous day's tea leaves, and re-heated porridge from the evening meal seemed to be fairly standard breakfast in Cekeza. Re-heating saves time and woodfuel but some nutritionists believe that it is not healthy and would argue against the practice.

A second implication for future energy use lies in the fact that almost half the total sample from both sites were school-going children who, within the next 1 to 8 years or so, will be entering the job market and may need access to electricity to create their own work. Unemployment among adult members of households was rife. About 80 of the adults in the total sample were desirous of employment but had none. Their children will have to be inventive about creating employment for themselves and the availability of electricity may help. Unemployment is a recurring theme and will be returned to later.

A third implication (of the low-incomes and high proportion of children) for energy use and social relations is the likelihood that children will increasingly pressure adults for energy for lights and entertainment whereas energy used for cooking food is unlikely to decrease proportionately. Of course these sorts of tensions, created by competing demands and aspirations between members of the household, are not confined to low-income homes. In many of these homesteads, the grandparent is 
not only the sole provider through his or her pension but also the primary caretaker. In these cases, such tensions may put additional stress on the elderly rather than between parents and their children.

Non-affordability of alternatives was given as the primary reason for continued wood use at both sites. Given the burden of this task as elucidated in following sections, this must be taken seriously. Non-availability and other non-economic reasons were given less weight in the discussions.

\section{Usual Daily Energy Use}

Multiple-fuel use was prevalent at both sites. This typical response demonstrates how the most common four sources of energy are incorporated into daily life:

Yes, I use wood, paraffin, and gas, because solar is not used for cooking. Wood I collect, paraffin is R10 for 5 litres, and gas $R 70$ for $19 \mathrm{~kg}$ for the fridge.

At Maphephetheni five energy sources were used. All 20 households interviewed had solar home systems. This means that they had two or three solar lights and connections for a small black and white television and/or a radio. All households were paying off their solar home systems, in addition to which most recorded some expenditure on paraffin and/or gas and radio batteries. This means that substantial proportions of incomes (up to $20 \%$ ) were being spent on domestic energy. Women still have the burden of collecting wood.

Energy use conformed to the usual patterns, urban or rural. So, although more accurate data are available, this report does not dwell on energy-use patterns. Eighteen of the 20 households recorded limited paraffin use, usually confined to small thermal applications such as ironing and sometimes water heating. The two households that recorded not using paraffin both reported not being able to afford it; however, they were committed to the considerable purchase of the solar homes systems, thus revealing interesting priorities.

Most households bought paraffin in bulk at the relatively low price of R1.20 a litre whereas paraffin bought in smaller quantities at the local shop cost about R2.00 a litre. Nearly half the households had gas-powered refrigerators and bought gas in town at R25 for 7 kilograms. Most of the refrigerators served a duel purpose: for bolstering income (such as freezing ice-lollies for sale at the school) as well as keeping food edible in the high temperatures common in the area.

Wood remains the cheapest of fuel sources since most wood is collected free of charge in both areas. But as is evident in the remainder of the report, the social and emotional cost of collecting wood is prohibitive. At Cekeza, 17 of the 20 households were electrified, 18 out of the 20 households used wood, 10 used some paraffin, five used gas for refrigeration, and most used batteries for their radios. The Cekeza area itself consists of rolling hills and grassland and not many trees, but white farmers in the area grow timber and allow some wood collection in them, so women do not have to walk as far as they do at Maphephetheni. Wood is also brought into the area by nearby timber farmers and others and sold for R70 a load for those who can afford it.

Paraffin cost R2 per litre at the local store-a fairly standard price - and gas was bought in the nearest town. Households spent between R15 and R150 a month on electricity. Half the households used electricity for cooking (but not always); only two of these used only electricity for cooking. Eskom charges a connection fee of R65 and most people had paid it by September of 1998. Prepayment cards were available at the store at Santombe, the next village. 
Questions about paraffin and gas usage confirmed trends that are already established, at least for urban areas (Annecke 1992; Mehlwana and Qase 1997). Limited quantities are bought and used in preference to wood, but dangers include emissions and the risk of fire. At Cekeza paraffin and gas use was even more limited than at Maphephetheni. Twelve of the interviewees said they used paraffin "sometimes" and seven said they could not afford paraffin. Gas was preferred over paraffin in one household with a regular income:

I use gas, it's cheaper and it lasts longer than paraffin, and we use it as an alternative to electricity.

Wood collection deserves a closer look. In light of the distress expressed by women in the following section, it is important to note how central a role wood plays in South African rural women's lives. All households at Maphephetheni collected wood. The typical response was:

Yes, I collect wood. I use it for cooking and heating water. We collect wood twice a week and it is scarce now. It takes almost the whole day to collect, which is about 7-8 hours.

Each woman brings home as much as she can find and carry, probably in the region of 20-25 kgs of headload. Several of the women complained that wood was scarce and that they had to walk further to gather it. This information agrees with the literature, but the interviews did not ask what women were thinking about doing to solve this problem - an omission which should be rectified in the follow-up study. Fortuitously, three women did offer their own solutions. All were thinking in terms of alternative sources of cooking power rather than increasing accessibility of woodlands or woodlots (there are none at either site). Two women considered electricity from Eskom to be the answer:

Yes, we collect wood, and we will never stop, not until we get Eskom electricity in the area and seemingly this will be in 4-5 years' time.

The third women suggested solar stoves as an alternative to Eskom:

Yes I collect wood. I won't stop until we get solar stoves as we hear there are those kind of stoves, or not until we get Eskom electricity.

Seventeen households at Cekeza (obviously including the three non-electrified) use wood regularly, 14 of these collect wood, four buy wood, and one household does both. For most it was the staple fuel:

Yes, I use wood for cooking, boiling water, and heating the place. I go to fetch them from the forest twice a week.

In some households children help occasionally, and in one particular household children, who had already spent three hours of their day walking to school and back, collected wood for their disabled mother:

Yes, my children, tired as they are after school, collect wood daily.

There were also a number of women who, poor as they were, bought wood because of a spirit who lured women to their deaths over the edge of a gully where they collected wood:

No, I don't collect wood; instead I buy some wood. The reason is there's a terrible place called indawo iwa lamfazi [the place where the women fall off]. 
While this is a perfectly sound reason for buying rather than collecting wood, it may be indicative of the lengths to which women have to go to justify expenditure on wood rather than some other necessity.

At Cekeza the three households that didn't buy or collect wood were emphatic about this:

No we don't collect wood. Not at all. Not even by mistake.

The significance of using a combination of electricity, gas, and paraffin lies in the daily decisionmaking efforts required of women. The tedious processes of weighing up what fuel to use, what food to cook, and the appropriate receptacle for the task according to availability and budget are necessary to highlight because they are little considered. In practice, these daily activities happen seamlessly without conscious effort to the observer. However in this tedious balancing act between empty stomachs and purses and the need to fill them, some choice is marginally better than none. There are woman who have to collect wood to cook porridge or there will be nothing to eat, and there are others who may buy wood, paraffin, or electricity. Women do not collect wood by choice.

Most studies of wood collection provide descriptions of who collects wood, where they collect it, how long it takes, what kind of wood is collected, how heavy it is, the consequences of this labor (back and neck problems, etc.) and other such valuable observations (Agarwal 1986; James 1992). This study offers an additional dimension: that of the women's views on wood collection. The real question for many is not "what fuel shall I use today?" but "do I have to collect wood today?" As is evident in the next section, the answer colors not only the women's days but their lives.

\section{Energy Use and Quality of Life}

This component of the interview explored how women perceived their quality of life and, in terms of the objectives, looked for evidence of increased appliance acquisition and/or income. Recognizing that quality of life, including the benefits of electrification, may be realized in ways other than material gain (such as time to rest, status in the community, and indirect benefits or satisfaction to individuals in the households), an attempt is made to give these less tangible factors due weight.

\section{Rural Black Women's Hardships}

Previous studies have celebrated the strength of South African women and rural women in particular, and have noted the stoicism of poor women (May 1997). They grit their teeth and get on with the job of trying to raise their children, finding scarce food and crude shelter, and, if asked, express the physical rather than emotional hardship of doing so. In an attempt to obtain an idea for the conditions of people's lives, respondents were asked what they considered the most difficult aspects of their lives. One of the reasons for soliciting this information was to gauge whether these hardships were of the kind that could be or were being addressed by development initiatives (in particular electrification), or whether personal hardship lay in realms best alleviated in other ways.

Most of the respondents were women who described a wide variety of painful and subjective experiences. In both Maphephetheni and Cekeza, women said that there was nothing hard in their lives, but meant quite different things by the statement (see the section on methodology). Most gave considered responses describing the drudgery of wood and water collection, ill health, poverty, and unemployment. 
At Maphephetheni, the collection of water and wood stands out as being the most dreadful part of women's daily lives. At Cekeza where electrification has brought some relief from this task, unemployment was the greatest hardship, followed at both sites by sickness, a lack of resources for development, and the physically hard work of building the homestead. Many women listed a combination of factors, but on average collecting wood was top of the list:

The hardest part of my life is fetching wood in the bushes for cooking, the sickness, fetching water, and fetching wood from the bushes for building.

The hardest jobs that we women in the rural areas do are fetching wood, water, looking after children, having no schooling, and not being allowed to work by our husbands.

Two women from Maphephetheni described going without a fire when it was raining. The first described having to exercise formidable discipline over using meager paraffin supplies, which would be admirable if it weren't such an indictment on the broader society:

The hardest times were when it had been raining and we didn't have dry wood to cook our meals and would go for days without food because we save paraffin for the mornings.

For the second respondent, being ill exacerbated the experience of having no wood in the rain:

When I had to go and collect wood and I was sick, my children were not there, it was raining, and I stayed without cooking for 2 days.

Cekeza's relatively lower incomes were evident in the high number of descriptions of unemployment, and again many respondents cited it among multiple hardships:

The hardest is the lack of employment, fetching wood, sickness like arthritis, high blood pressure, and others that are so hard for me.

A significant number of women, about a third of the households at both sites, complained that the hardest part of their lives was that they were always ill. In addition to those cited above, the following examples show women who put this illness above other hardships:

The hardest is that I am always sick, [have] no work, there is a lot of poverty here, and we always have difficulties because there are no resources here.

Being ill is the hardest part, doctors say that it's TB and high blood pressure. Sometimes I can't fetch water and can't even do my own washing. Cooking one can't do.

Sometimes the progression of the illness was slow:

There hasn't been any of the hardships but the only thing I can comment on is that I am now sickly every day when I used to be sick only some weeks.

For some the expectation that conditions in the rural areas would improve and the perception that they haven't is a disappointment hard to bear:

The hardest thing is the life that we lead in rural areas where there is no infrastructure and no development taking place, although we hear others do get development. 
Some women identified electricity as a positive contribution to their lives:

When we didn't have electricity it was very difficult. It is still difficult, but it's much better than it was before.

But a group of women at Maphephetheni expressed their disappointment in solar:

The fact [is] that solar is no different from not having electricity in the area. We need Eskom electricity then we'll feel the difference.

The natural grief of four older women, for whom the cruelest circumstance had been the deaths of their husbands, seemed to accept the grim socio-economic hardships and the brutality of South African life. One woman spoke of an unpunished murder as the hardest time of her life:

The hardest was when my eldest daughter passed away after being raped and stabbed by her boyfriend. And also he brought the dead corpse and dropped it in front of the main door to the house.

High numbers of low-level, chronic illness is not a new phenomenon among low-income women and is not confined to rural areas (Annecke 1992). Although the HIV virus is reportedly spreading at a rapid rate in South Africa, this did not appear the cause of women's complaints. There were young women in both areas who had "come home" from work places in urban areas and were too thin and ill to contribute to the household or domestic chores in any way. These may be HIV-positive cases, but the women we spoke to were middle aged or older and said they had had these complaintsheadaches, high blood pressure and "a sort of achey-flu"-for years. The women reported that the chronic fatigue resulting from their ailments affects their ability to collect wood, maintain the household, work in their own or communal gardens, or engage in any activity in the evenings. In Cekeza, it was clear that electricity offered substantial relief from wood collection to those who were already using it for cooking, and, as became evident in the next part of the discussion, substantial hope for those who anticipated using it in the future.

It may be worth pointing out that being without wood for 2 days during the rain means 2 days without cooking, which in turn means being without food. There is no bread in these households, no fast foods, biscuits, or cookies, or anything other than salt, mieliemeal, tea leaves, and sugar. If paraffin use is rationed for boiling water in the morning and there is no wood, there is nothing to eat or drink other than water until the next morning. This highlights the dependence of some households on a regular supply of free fuel and the need to think creatively about poverty alleviation in South Africa.

\section{Quality of Life Perceptions}

In this part of the conversation, women were asked to discuss the best or better parts of their lives. The purpose was to see whether conditions such as basic needs and energy-use patterns played a part in the assessment of the quality of their lives, and if so whether these were changing for the better. For some, electricity has made a significant difference. Just as wood collection was the worst part of many women's lives, so receiving electricity was described as the happiest moments of many lives. In Maphephetheni, 11 of the 20 women said that their solar home systems were among the best things that had happened to them. The proportion was even higher in Cekeza-where 11 out of 17 women described the joy of being connected to the grid at last. 
But asking poor women about the better or best parts of their lives frequently revealed levels of deep distress rather than any gladness. Over a third of all the women-six at Maphephetheni and five at Cekeza-felt that there was little in their lives that was good or happy. Several said simply:

There are no happy parts in my life.

A weary woman at Maphephetheni said:

There is nothing good in my life because I am still suffering and a pensioner who has to support all the children.

Having put her trust in the democratic process, a woman from Maphephetheni shook her head despairingly and said:

I cannot talk about the good parts. There are none. There are no good parts of my life, because we voted but there is no difference in our lives.

Another respondent mused:

There is nothing good in my life except for going to church.

One woman, perhaps more optimistic and hoping that conditions will improve, said:

I haven't seen any happiest parts in my life as yet.

On the other hand, the two-thirds of women who could find some joy in their lives articulated a variety of experiences, many of which included electrification. Some drew a link between historic elections and delivery:

The best part of my life was the 1994 elections. Well now after I've got electricity installed it is even better because I have long wished that I can watch my television.

While others pointed out the benefits of electricity and development to be derived by the entire community:

When we got electricity that was a true blessing because we all knew that our problems would be lessened.

The best thing is to see that at least development is coming for all of us, because one of the local schools has got computers because of the solar we have got nowadays.

There was a marked difference between the degree of satisfaction expressed by those with solar systems and those with grid, the latter being more satisfied. Perhaps because the levels of hardship at Cekeza were in many ways worse than Maphephetheni, there was great and spontaneous delight at having electricity at last.

...to have electricity made me very happy even though I can't afford all the appliances.

Some commented on electricity's safety and the added security it offers to a tenuous existence: 
To have electricity makes me so happy because I no longer buy candles and now we are safe because electricity is safe.

Having electricity in my house is less dangerous than candles that can burn out easily and cause me to lose everything.

The buyers of the solar home systems were less enthusiastic. Several women said that some improvement was better than none:

The best is now I have electricity in my home though it's incomplete, but half a loaf is better than none.

Others said that although solar home systems had made their lives easier, they really wanted something better. There was a small but vociferous group for whom solar constituted no improvement at all:

There are no best parts of my life, because life is still the same since we do not have enough electricity.

Such negativity in denying the worth of a solar home system (which the respondent had chosen to buy) can be read to reveal the desire for electricity as a primary rather than secondary energy source.

There were those for whom electricity was important—but as an afterthought:

My son bought me the nicest blanket in the world and is so expensive. I am never cold now. He also bought electricity.

Among those who didn't mention the contribution of electrification to their lives, one declared that:

...having my family together for once in a lifetime was one of my happiest times.

The issue of unemployment was indirectly raised:

When my husband was still working it was very nice. Those were the happiest moments....

And a variety of different responses indicated that there was no pressure or guidance to speak about electrification:

The best thing in my life was...

...having three beautiful children (though illegitimate).

...when my son Siyabonga bought a car for the family.

...when my sick daughter, Goodness, came home from hospital much better in '96. She was 20 years then and we thought she was gone forever.

Two teachers at Maphephetheni expressed satisfaction with being able to do their schoolwork at night using solar lights. At Cekeza, the teachers' quarters at the school were electrified, but the teachers said they didn't work at night. Instead they did their preparation in the afternoons or during their 'free' periods at school. 
The significance of these responses is the degree to which electrification, but particularly grid electrification, makes a difference in women's lives. While there is a strong possibility of bias towards my personal area of interest and the findings should not be taken too literally, over half the sample described buying a solar home system or being connected to the grid as one of the happiest moments of their lives. This satisfaction was tempered by reservations at Maphephetheni that the "electricity was not enough." Comments like these came as responses to next question, which asked directly whether electricity had affected the quality of life.

\section{Energy Use and Ease of Life}

This was a straightforward question testing the assumption that electricity makes women's lives easier. We also tried to assess how future energy-use patterns would change based on the answers.

Responses from the households at Maphephetheni were ambivalent on this issue, reflecting the limited applications offered by solar systems. Overall they tended towards the negative (55\%). Nine respondents $(45 \%)$ were positive about having solar lighting and connections for the televisions, four $(20 \%)$ were uncertain whether solar had made a difference, and seven $(35 \%)$ were adamant that electricity had not made their lives easier. Here are examples of the three positions.

Those who were delighted (45\%):

Electricity has made a lot of difference to my life, because I manage to sit up until late without any fear that the candle is going to set fire to the whole house.

Those who were ambivalent (20\%):

Not that much, electricity has not made that much difference because women are still fetching wood for cooking, buying paraffin and gas.

Those who were disappointed (35\%):

No, electricity has not made any difference because I still cook on the floor as before and I still use candles for lighting.

Each of the three positions has implications for energy-use patterns. Instant, strong lighting was appreciated and several respondents approved of the fact that the lights heated their homes.

In many ways electricity has made my life easier because even if I visit friends when I come back home I simply switch on the lights and my home is bright enough and warms up quickly.

The ambivalence expressed by four of the respondents at Maphephetheni and the disappointment of another seven related in each case to the fact that solar does not replace wood collection and cannot be used for what is the most arduous task-cooking. This is a key issue, which comes up repeatedly in the study and needs to be addressed.

Health and safety are important socio-economic determinants of energy use, and women were clearly aware of the dangers of candles. Four women at Maphephetheni spontaneously mentioned the improved safety factor in using fewer or no candles. The dangers of thatch and candles were raised in the groups. While most women believed that they would have to have solar lights in all the huts before they were really safe, a step towards this provision remains a positive dimension of the solar home systems. 
At Cekeza, more positive responses indicated that most thought that electricity had made their lives easier. It may be that electricity was still something of a novelty since it was installed only nine months previously, but 15 of the 17 who had electricity were overwhelmingly enthusiastic. For example:

Yes, electricity makes my life much easier because we no longer buy candles for lighting and one day I will have a stove and I won't have to fetch wood again.

Yes, now I cook anytime without any hard work, make tea anytime of the day without first making fire.

Yes, because I cook quickly, boil water quickly, drink tea anytime of day, and listen to my radio anytime.

Yes, it has because I have enough time to do other things, like I visit my neighbors and it's daily that I used to cook on wood so that's a load lessened.

Of the five who said that electricity had not made a difference because they still collected wood, three were not connected, while another couldn't see her way clear to using electricity to the fullest degree:

Not at all. Electricity has not made my life easier because I cannot enjoy cooking with it, making tea anytime because I can't afford to buy those appliances.

And one respondent expressed the optimism for the future typical of many of this group:

Electricity has not made my life easier. Not that much, because I still use wood for cooking but as soon as I can afford to buy a stove I will smile to myself because I won't ever use wood again.

Common sense and middle class experience may be enough to confirm the assumption that electricity makes life easier for women. But, middle class experience can not express the frustration of women still having to collect wood despite substantial outlay on solar systems, nor articulate the hope and aspiration of those that will somehow buy stoves and will not have to collect wood again. Belief in this future, easier time makes life easier ${ }^{4}$. This hope is what distinguishes the women at Cekeza from the women at Maphephetheni, at least in terms of energy supply.

\section{Appliance Acquisition}

This question was asked to attempt to measure appliance acquisition over time as an indicator of changing energy-use patterns and improved quality of life. The question also explores whether the answers to this question correspond with the subjective experiences above. To a large extent they did. Given the economic constraints of rural communities, we were interested to explore what appliances had been acquired since electrification, which were in use, what had influenced the acquisitions, and what energy-use patterns were consequently discernible.

In the case of the solar home systems at Maphephetheni, we did not expect to see a surge of new appliances other than televisions and/or radios. The solar homes systems had been on sale for the past 3 years. Those who bought their solar home systems in 1995 and 1996 had both radios and

\footnotetext{
${ }^{4}$ Crawford-Cousins calls this the "politics of hope."
} 
televisions. Of the eight households who bought systems in 1997, only one did not have a radio and all had televisions. One of the two households who acquired their systems in 1998 had neither a radio nor a television - the other had both. Thus it would appear that within the first year most households begin to use their solar plugs for television sets, although many radios were still battery powered. There may be a niche market for inexpensive electrical connections for older radios.

When asked about appliances, several women expressed regret at not being able to use electric irons and kettles, confirming their earlier ambivalence about solar home systems:

I 've got an iron and a kettle but it's such a pity I can't use [them] because solar doesn't have any appliance plugs.

Most households "had enough electricity in the battery" for their lights and televisions at night; only three said it "ran out" before they were ready to go to bed.

At Cekeza, households were connected late in 1997. There was a noticeable trend towards buying small appliances first with several households looking forward to buying stoves. Eleven of the 17 households reported buying one or more electrical appliance since electrification, including four irons, four kettles, a radio, and three televisions. In addition, five had bought stoves of some sort and others expressed their aspiration to do so:

Yes, I have bought an iron, and I'm going for a kettle, television, toaster, fan, and all those things that make a person's life a lot easier.

Households with only one income were at a disadvantage because other possible earners could not contribute to buying appliances:

My daughter has these things, she buys them for us, but not me-but I contribute food.

My son buys all of them for me. I only buy food. He bought me something for Mnet ${ }^{5}$ but it's not working, and even a video machine that I can't use.

Generally, respondents were realistic about what they could afford:

I try every time that I see something I need to buy it. I'd love to have things that other people have also but I can't.

Yes, we buy whenever we have money, but we are still battling a lot to buy what we need.

Nonetheless, a number of appliances had been bought post electrification at both sites. Over 3 years, almost all households (80\%) who had bought solar home systems also bought televisions (small black and white ones). It will be interesting to see in the next year whether more stoves or televisions are bought at Cekeza where there is the possibility of operating both. Thus, it would appear that energyuse patterns are beginning to change as small appliances are bought and used and the intention is to use stoves more.

\footnotetext{
${ }^{5}$ South African Cable Network
} 


\section{Status in the Community}

It has been argued that development should include personal empowerment as well as economic development, and that the process of electrification could lead to empowerment of people through participation in informed decision making about electrification (James 1996). It has also been argued that the empowerment of poor, black rural women, who are at the bottom of the social order, should include raising their self-esteem and self-confidence (RDP 1994).

Asking whether electrification had given the recipient status in the community was a deliberately blunt question. It did not attempt to address process or self-growth; it was intended to assess on a superficial level whether electrification elevated self-esteem. If electrification is seen as a status symbol, it may be accepted or rejected for reasons not immediately apparent to an outsider. Perhaps in the follow-up study, questions about the process of building self-esteem could be asked instead. The question nonetheless yielded some interesting responses.

At Maphephetheni, 10 respondents reported no improvement in their status because they still had to collect wood. Most were resentful of this:

No, electricity has not given me status because I still go to the bush with everyone who doesn't have electricity to fetch wood. Our lives didn't change at all.

Seven women recorded a positive increase in their status when they bought solar home systems. They gave a variety of reasons for this, including that having lights made living in a rural area more tolerable and more like 'whites,' or that having electricity was just one facet of an upwardly aspirant household:

Yes, electricity did give me status because that shows me that I like development and I can manage it. And I feel proud because of my child who is a teacher because she does everything for us.

And then there was the sad reply:

I don't know if electricity can give me status. I haven't evaluated myself yet because I don't have pride at all.

At Cekeza responses to this question were fairly evenly weighted. Eight said having electricity had given them status in the community and made them more like urbanites:

Yes, we are now not different from people living in urban areas.

Nine said electricity had not given them status in the community:

No, most of us have electricity. I'm no big shot to have lights-we are all alike.

Three weren't connected, and said they didn't know but would like to have the status and convenience electricity provides.

The status conferred by electrification did not seem to yield much power. Indeed, several women asked why it should since "we are all the same." In Maphephetheni, some women wanted the same for their neighbors as they had bought for themselves. This was evidence of an egalitarianism also 
demonstrated by those at Cekeza who argued for those who had not yet been grid connected and insisted they be represented in the sample.

\section{Rest and Leisure}

It is assumed that providing electricity will lead to an improved quality of life, which may include more time for leisure or rest. Judging from the discussion ensuing from the question, "Do you have enough time to rest?" the saying, "A women's work is never done" must have originated in a rural area. Most women indicated they did not know what rest meant.

At Maphephetheni, 14 of the 20 respondents (70\%) strongly believed that they did not have enough time to rest while six believed they did. This assessment was based largely on patterns of wood and water collection and who was responsible for these tasks in the household. Those who didn't have time to rest said things like:

No, I'm forever working night and day.

One woman who thought she did get enough time to rest excluded the days when she had to collect wood:

Yes, I do have time to rest, why not? Because I cook on wood and sit and rest the whole day, just unless I have to gather wood on that day then I'm tired.

One woman escaped household chores only by exchanging it for gardening:

Totally not. I never get time to rest unless I go to other areas like the garden to check on the vegetables.

Interestingly, the numbers were reversed in the Cekeza sample. Eleven women felt they did have enough time to rest, primarily because they didn't have to collect wood-they either bought it, had someone else in the household collect it, or used electricity:

Yes, because I don't have to fetch wood, I have another way for cooking.

Yes, because I have a stove for cooking.

But nine still felt the physical burden of being the wood collector and primary care giver:

No, I never have time to rest because we still fetch wood, which is the most difficult part.

No, women in rural areas have a lot of work every day.

Not that much, I don't have that much time to rest because I still have to fetch wood, water, and go to sewing groups.

No, I can't rest because I must always get food for these children.

Sufficient time for rest and leisure are important signifiers of quality of life. Insufficient rest is clearly related to wood collection and affected by low levels of energy or a high incidence of illness, but it is also a feeling. The perception that tasks are never-ending tires many women, especially those who are older and caring for grandchildren. These grandmothers raised and educated their children in 
anticipation of being looked after in their old age and instead they are physically and financially (via their pensions) looking after their children's children. Rest, even in their old age, escapes them.

\section{Beneficiaries of Electrification}

Women were asked who benefits most from electricity to determine current and likely energy-use patterns. The responses showed egalitarian views of shared benefits and hardships for all members of the household.

At Maphephetheni, the most common perception (nine out of 20) was that all had benefited equally from the bright lights. There was a trend towards singling out children as beneficiaries, particularly in homes with a television. Seven women said the children benefit from being able to do their schoolwork at night. In the remaining households there was a specific person, such as the grandfather who watched television or a daughter who was a teacher, who was perceived to benefit most. Here is a generous-spirited response from a mother:

All of us benefit from electricity because we use it and more especially the younger ones. They help me though and then I rest more often than I used to.

The same number (nine) of respondents at Cekeza believed that all members of the household had benefited equally from electricity and all mentioned lighting as the primary benefit:

\section{All of us because we all enjoy bright light.}

But Cekeza responses were unlike Maphephetheni in two respects. There were six respondents at Cekeza who believed that women had benefited most whereas there were none at Maphephetheni, and these included women who did not yet have stoves:

Women, because they are the ones using electricity more for cooking, ironing and all things in the house.

Women have benefited most because it has removed most of the hard work especially for cooking.

There were only three households where children were mentioned specifically using light for homework and a beloved grandchild who "did crayoning at night."

The three who didn't have electricity didn't know who benefited most, and a very tired 72-year-old said:

Every other person besides me of course, I'm hard working and I'm strained because I'm the only one working and getting pension.

The study confirmed that the primary benefit is lighting, and that this is shared by all members of the household, in particular those who work at night. An indirect benefit to everyone was the safety aspect of fewer candles. Secondary benefits to solar home system owners include televisions, and for those connected to the grid, the convenience of small appliances within the first year.

In the course of conversation, women were also asked who in the household had better or easier lives. The intention was to explore whether women or men spontaneously identified roles or people within the household who lived better quality lives than they did, and whether this included greater access to 
or control over electricity, thus influencing the energy-use patterns in the household. At both sites most respondents thought that all members of the household had equally difficult lives: it was framed like this rather than in terms of equally easy lives. Considering their workloads, women displayed relatively little resentment of other adults in the household. This may be partly because all their lives are so hard (as many said), and partly because those men and women who are at home either provide an income, for which the woman is grateful, or suffer in their own way from not being able to do so.

That all their lives were difficult was not in doubt. There were clear reasons given:

I don't see anyone in my household with better life since there is no one working and we are all depending on this pension.

I don't really know. All of us have the same lives, we don't make a comparison.

There were a number of thoughtful responses with women showing their generosity rather than resentfulness at the multiple roles they performed every day:

All of us are equal at home, it's only that I use it more than any other because I cook and make food to sell.

In this household no one is better than the other, we are all equal because we all benefit and help each other. For instance, with the little knowledge I have I help my children do their homework.

If any group was thought to have consistently easier lives it was the children, and electricity played a part in this:

The children have better lives because they do attend school, which I didn't, they use electric light for studying, and can watch television if they like.

Three respondents named specific people who benefited from electricity. One of these was a beloved grandchild whose safety was also a consideration:

My grandaughter because she does her homework under good lighting and around her there is a safe environment.

One respondent at Cekeza made reference to the macro-environment and changed political conditions as providing conditions for improved lives:

My children and grandchildren will have better lives. They still have a long time to live under the new government. If good comes they'll benefit even more.

Another respondent made reference to inner happiness rather than worldly conditions:

My daughter is better and has a better life than I do because she does good deeds unlike me. She is forever smiling and she never gets upset.

Thus at both sites the primary benefit from electricity was light. This was to everyone's advantage but especially the children, who were perceived to have easier lives at this stage. This confirms earlier research and intuition. At the off-grid site the greatest benefit was to children through television. Significantly, at the grid site there were fewer televisions. Several women indicated that they were the 
primary beneficiaries of electricity because their workload was (or could be) reduced, if not immediately then over time. It would appear that low-income households anticipate increasing their energy use over time and that energy-use patterns will alter as they use more electricity and less of other fuels, primarily wood.

\section{Income Generation}

It has been argued that improved quality of life is related to improved income. According to the literature, providing electricity may contribute to this by providing light for "longer days," which may allow for additional income-generation activities. These questions tested this assumption and began to quantify the number of activities in which this held true.

Extending Daylight Hours: Morning. Respondents were asked whether, once they had electricity, they got up earlier or went to bed later. The question was not well asked or understood because most respondents who said they got up early explained that this was for school going children and was not necessarily affected by electricity. What we really wanted to know was whether there was some respite for women who had electricity in not having to make a fire in the mornings. Thus this should be asked directly in the follow-up study.

At Maphephetheni, most women (17) said they got up at the same time as they had before or "in good time." Thus, having solar home systems seems to have made little difference to energy-use patterns in the early morning. Of interest were two households where men were acknowledged to assist with getting the children off to school. One of these was the progressive Inkosi:

\section{Yes, I get up early because I help around with some basic chores.}

At Cekeza, seven women said they got up early but this was largely to prepare children for school. Some did take advantage of electric light to do schoolwork or domestic chores:

Yes, I get up early because the light is bright enough to allow me to do other jobs.

And as in Maphephetheni, the new age man has made his appearance in this rural area, too, bringing great relief to an elderly pensioner:

No why should I get up early? My son does all the chores, helping his sister prepare the school children.

Most respondents reported not getting up at any different time, but pointed out that having electric lights made it easy to get up early if they wished to. Marginal changes are likely in the mornings at off-grid sites with more noticeable changes at grid sites where the intention is to use electricity more. Much will depend on affordability.

Extending Daylight Hours: Night. In Maphephetheni, six respondents said that solar lighting offered no possibilities for working at night. But a significant number, 14 of the 20 respondents, said that although the light could give them more time to work at night, the electricity could not:

...because solar is only used for lighting and not for plugging anything into.

They said that those who weren't too tired from collecting wood would work at night if there were something to do, but they didn't know what this might be: 
Electricity could be used if I worked at night, it's only that I don't have something to do, and I'm tired.

I don't work at night. The only thing I do is sit and watch television.

The latter was not so much because she didn't want to make money, but because she had little idea of how or what to do:

Now, if you have a plan tell me....

Four out of 20 people used solar lighting for school, administrative, or income-generating work. These were a teacher, the Inkosi, the woman who made Zulu mats, and another who made ice-lollies:

I use solar lights a lot: I do Zulu mats at night, but when I feel very ill I don't do them.

Yes, we make ice-blocks at night [in a gas fridge] so we can sell them to the scholars at the near-by school and we keep them nice and cold.

The women who made Zulu mats was very positive. She said:

Yes, people can use electricity at night and to help them earn money. A lot. If they start up good things like small businesses, and also take care of themselves so that the government doesn't leave us struggling.

And there was a timely reminder that working isn't just about making money:

Yes, I use the electric lights to read the Holy Bible-that to me is working.

Interestingly, though electricity at Cekeza was used primarily for lighting (in this way similar to Maphephetheni), there was a strong perception (15 people) that it could be used in income generation. Indeed, seven respondents pointed out examples of how they used their electric light to work at night and most used an electric appliance as well. They said:

Yes, I use the electric light to work at night, because I do my sewing at night and sell the clothes in the day.

Yes, I use them at night; that's when I make my ice-blocks.

Yes, I use the electric lights to work; I cook some of my popcorn at night and the children take it to school [to sell].

Yes, I sew some jerseys for my sons and my granddaughter, Promise-I want to ensure that she's always warm-so any other person can do the same.

Yes, of course who doesn't know that? We make ice-blocks and also sell some ice cream and also make hot potato chips and fish.

The latter was the household who spent R150 on electricity a month and it would be interesting study to know in the follow up what sort of turnover and/or profit she made. 
Eleven women at Cekeza said they didn't use their extended days for money-making eneterprises but did not rule out the possibility in the future:

I'm sure electricity does give you time to work at night it's only that I don't do any work at present.

Yes, you can use it because they can buy fridges to sell from or do any kind of business.

They were toying with ideas:

I'm now thinking of doing the same, so yes, people can use electricity to earn money.

Then there was the woman who said:

Yes, people can use electricity for making money at night, but I don't have any money to buy appliances.

Three said they didn't know if electricity could assist with income generation and only two said that electricity could not assist with income generation.

Thus, except for the woman who made Zulu mats, there was a strong perception at both sites that, although solar provided light at night, income generation was tied to "plugging in appliances" (such as the gas fridge) rather than using the light for doing creative handwork, for example. Noteworthy once again the idea that light is not enough, one needs some finance to buy [plug in] equipment to start a business. This was the case in terms of refrigerators, stoves, and a sewing machine. The market for these goods was intra-community whereas the market for Zulu mats was not.

In a final probe of possible uses of extended days, women were asked whether electricity had made a difference to how evenings were spent. In response, 11 of the interviewees at Maphephetheni said no and six said yes. Of the latter, three gave watching television as the reason. At Cekeza, eight said that having electricity had changed the ways in which they spent their evenings. There were some new reasons given for this:

\section{Yes, I go to bed later after sitting admiring the light.}

Another emphasized that a woman's work is never done:

Yes, ironing the uniforms, etc. and making lunchboxes.

And for the lonely or the addict:

Yes, I go to bed late from watching more television until very late at night.

The seven micro-enterprises at Cekeza are all home-based enterprises done largely in the evenings using electric lights and small appliances. The scoping study did not determine whether they made a profit or generated only turnover. This would be worth examining in the follow-up study. What these activities did do was provide an avenue for creative output and an active engagement with life not evident in the poorest households. The involvement of seven out of 20 households in a poor area in some sort of commercial activity within nine months of electrification seems encouraging and worth supporting. The households using electricity for cooking showed the greatest shifts in energy use and would be worth following up. 


\section{Health and Safety}

Health and safety, particularly women's health, is an important consideration in the selection of domestic energy source. Where there is choice, for example not having to carry wood, reducing the smoke of wood fires, or choosing the safety of solar above candles, different women appear to exercise these choices in different ways. But there is also a level of well being that affects all members of the household depending on the well being of the primary caretaker. As was evident in the responses to the question about the hardest parts of rural lives, chronic illness plays a significant role in making women's lives miserable. The incidence of high blood pressure and perpetual headaches was high, in addition to which several women complained of having tuberculosis and undiagnosed illnesses:

In February 1998 I almost died. I had a running tummy and vomiting and I was also having fits. I almost died because the doctor also couldn't help at all.

Thus, although the study focused on household energy use, a question was asked about healthcare available to women in terms of clinics, whether these were electrified, and whether electricity had improved the service they received. There was very little healthcare support available to rural women. Mobile clinics operated at both sites on a bi-weekly basis. At Maphephetheni there are buildings suitable for day clinics, but no staff. At Cekeza, the mobile clinic operated out of a vehicle. A holistic approach to healthcare requires a multi-pronged approach, but since clinic services are unlikely to improve in the near future, a good start would be to relieve women of the need to carry wood and to speed up the delivery of water.

Women's Safety: Night Lights. The final question in this section asked if electricity had allowed women to move around more safely at night. If there was one question that everyone was pleased to be asked and answered positively, this was it. At both sites the Inkosis and other men answered as enthusiastically as the women did. There are no streetlights in either area, but women were overwhelmingly positive about their and other people's outside night lights. Parts of the conversation give us an indication of the affect of lights at night on women's safety. Two young mothers said:

Yes, I'm sure electricity makes it safe for all women and it is even good for me to know it is there although I am never late at home.

Yes, when I'm coming late from church in the dark now I can see by the electric lights any person who tries to do wrong.

In a country with one of the highest incidences of rape in the world, it is important to ensure women's safety and ability to participate in community activities that may be held in the evening. Night lights and/or streetlights, possible off-grid mast lights, are an area of work for the future.

\section{Optimism for the Future}

This question was designed to gauge respondents' confidence in the future by asking, "How will your children's lives be in comparison with yours?" We wanted to know if people saw any improvement forthcoming in their own or their children's lives, and what role electrification would play in this.

At Maphephetheni, most of the respondents (15 of the 20) believed that their children would have better lives than they had because of "development," including electricity coming into the area and 
the fact that attendance at school is obligatory (although there were homesteads where children were not at school). A typical response was:

Our children's lives are better compared to [ours] because we didn't have access to anything. Now they use computers at school, use libraries, they have more chances than we did.

Change is unsettling-five people at Maphephetheni were uncertain if the changes would offer better lives or how to define "better:"

I don't know because there are a lot of changes bad and good so it's very hard to predict or know what their lives will be. It's difficult to say if they will be happy.

At Cekeza, adult opinions on whether or not the children would have better lives hinged on two primary considerations: whether the children took advantage of the improved schooling offered to them and whether there would be jobs for them. There were six who argued forcefully:

Our children will be in a big mess because of unemployment.

Our children's lives will be a nothing because they finish school and sit at home because there [are] no jobs.

Our children's lives will be difficult if the present situation of unemployment goes on.

I don't know, because I don't see any improvement because the children are not working. They say there are no jobs.

Two added caveats:

Our children's lives will be better if the government will create more chances of employment.

I'm not sure if their lives will be better because jobs are scarce, but I assume they'll be better than mine because they'll have better houses than ours.

The nine who believed that their children's lives would be better than theirs said:

They will be a lot better because technology has improved many things and therefore they will benefit from what we didn't have. For instance I have std $9^{6}$ at 29 years, which is not bad, but I want them to go to college, technikon, or university.

Their lives will be much better if they see the importance of education as I see it now.

Our children's lives will be much better because of the changes taking place in communities, for example we have creches and electrified schools that we didn't have before.

Our children's lives will be better because of the development taking place.

Respondents were specific about this:

${ }^{6} 9^{\text {th }}$ grade 
...because rural areas are now more developed -we have a creche and electricity, but we still need a clinic and water.

While one woman made it clear that she had not reached the land of milk and honey:

We'll see as time goes whether the children will have better lives, I don't know, Mandela is selfish, we were better in Egypt than now.

Discussions revealed that education, lights for homework, and electricity at schools were perceived as important factors in improved living conditions. The general trend was towards optimism for the future. However it was especially noticeable at Cekeza that people's assessment of the likelihood of improved lives for the children was tempered by their experience of a lack of employment opportunities.

\section{Participation in Electrification}

The final question in this section was how people heard about electrification and how electrification arrived in their area.

In the case of Maphephetheni, Cawood's demonstrations, sales woman Dorcas' persuasion, and seeing or hearing from others all played a role in the awareness and purchase of solar home systems. At least eight of the 20 owners had attended Will Cawood's demonstrations, and many could name him as pivotal:

Will Cawood came to do the demonstration with another guy and then we had to apply if we liked it. We did, so we went to Dorcas and it was then spread in the village.

Dorcas has been a successful marketing agent too:

I saw a note in the local supermarket with Dorcas's photo telling us about solar so I went to Dorcas and ask the whole information-then I got electricity.

Exposure to the possibility was enough for others:

I don't know how it came here, I just saw it in the village and I was pleased and happy and wanted it also.

In the case of Cekeza there was, perhaps understandably given the history of on/off electrification from Eskom, little clarity about the process of electrification or specific people involved in it. Nor did this appear to be an issue for those who were eventually connected. Thirteen of the respondents said they didn't know how the process had happened:

I don't know how electricity came here. But I know that we are grateful that it came to the village taking the drudgery off our shoulders.

I don't know how we got it. I just saw people coming to our houses asking whether we want electricity or not, then after a long time we saw electricity here.

Four recognised the role of the Inkosi in applying for electricity, and there did seem to have been a meeting at some stage: 


\section{I don't know, I just heard rumours that the chief brought it.}

The chief called us to the courthouse and told us about the electrifying of the area.

Thus, word-of-mouth, advertising, and demonstrations have produced a slow but steady growth of off-grid systems. For most that get connected, the grid came out of the blue for all homesteads in a particular area and everyone was pleased to see it. The problem in Maphephetheni was that the grid was not going to be extended to the area although it had been extended to the adjacent area. The Inkosi was particularly angry that there was no mechanism within Eskom for receiving part-payment from the community. The Development Forum had set aside over a million rand of their RDP funds towards electrification but Eskom could not engage in negotiations to use this.

In Cekeza, there was a great deal of anger and frustration about those not on the map and not electrified, although the Inkosi's homestead, which was several kilometers from the spine, had been. Education about energy use and conservation were minimal at Cekeza; at Maphephetheni the solar home systems were relatively well understood.

\section{Non-Formal Education}

This section of this study attempted to examine the assumption that providing electricity to rural areas will enable better light for reading print media and access to electronic media, such as computers, radios, and televisions, that will lead to improved, local general knowledge and will facilitate participation in the modern world. Changing energy-use patterns should substantiate shifts in time use.

Considering the importance of outside influences on our everyday lives, and contrary to expectations of lively discussions from avid television watchers and radio listeners, this section raised little enthusiasm in the structured interviews. Invitations to discuss programs and content were often met with monosyllabic responses to what should have been lively topics of conversation. This may have been due to the respondents' fatigue, as well as unexpectedly low ownership in Cekeza. In the followup study the section on non-formal education should be separated from that on quality of life. There is also provision in the follow-up study to obtain advice from cultural studies experts such as those at the Universities of Zululand, Natal, or Rhodes, or the South African Broadcasting Company.

The question about what people learn from the radio and television needs to be asked in two steps because it is something that most people had not thought about. Consequently people treated what they watched (mostly soap operas and sitcoms) lightly, which may appear to be the sensible approach, although theorists such as Horkheimer or the Frankfurt school would argue the inadvertent power of style, ideas, and advertising on global aspirations.

\section{Question 1}

Do you have a radio and/or a television? Is it powered by batteries or electricity?

This question provided an interesting quantitative context for the ensuing discussion. At Maphephetheni there were 18 radios and 19 television sets in 20 households. Fourteen of the radios were bought before the solar systems and were battery operated. The televisions were all solar powered but two were not working because of some fault in the solar system. One respondent said she didn't watch television at all and had nothing to say about it. Thus, at Maphephetheni, 16 of the interviwees were regular television watchers. 
It is commonly believed that almost every household in South Africa, rich or poor, urban or rural, owns a radio. This was not the case at Cekeza where the penetration of radios and televisions was low. Less than $50 \%$ (nine) of the households owned radios and 36\% (six) owned television sets. However, this number may rise considerably now that the area has been electrified. Three of the radios and five of the televisions were bought post electrification. So, in just 9 months, ownership had increased five-fold. This low viewer and listenership made it difficult to draw comparisons with Maphephetheni. Nonetheless, there were some interesting responses from both sites.

A shortcoming of the interviews and the discussions was an account of how these poor households paid for solar home systems and televisions. The standard solar home systems power only small black and white televisions. Even in South Africa these are relatively inexpensive (about \$80), but this represents a full month's income in several of the families and probably twice that if bought on leaseto-buy terms.

\section{Question 2}

Tell me about the television programs you watch, which you like most and least, and what you learn from them?

At Maphephethini, the news was the most popular program. Fourteen of the 16 households watched the news. One of the women who didn't watch the news said it was her least favorite program. The other said soccer was her least favorite program, offering telling glimpses into household dynamics about who chooses the program. In both these cases it would appear that the woman does not, and this may be symptomatic of decision-making processes or access to resources worth following up in the next study.

Other popular programs were the soaps, quiz shows, a South African sitcom called "Generations," and a new South African serial called "Isidingo." Most of these are in English but Zulu language programs were also popular: "Ezodumo" and "Umqambothi" were both mentioned more than once. Several people also mentioned enjoying African music. Global events, however, drew critical comment:

The children watch KTV and we watch Days, Bold, Generations, and also news. Events in the world are so terrible though; it's such a pity. Now we know how bad it is everywhere.

The Inkosi had a particular reason for watching the news and documentaries:

Most importantly I watch the news. I need to know things that pertain to the interests of the people in the country and how other chiefs operate in other areas and other countries.

At Cekeza the news was again the most popular program with the soaps coming second. The scoping study established that the people at Cekeza, and in particular teachers, showed a high degree of awareness and understanding of events in the news:

I watch all the Zulu shows and the Xhosa and Zulu news and now I know that Kabila [President of the Democratic republic of the Congo] is in Durban with Mongameli [President Mandela].

I watch all the nice programs, especially the news and the CNN news. These days the heads of state are in Durban and Mandela is welcoming them.

The best things right now are the NAM summit and the anniversary of Princess Di. 
Since this is a relatively isolated community with low media ownership, an understanding of why this is so may be important to encouraging participation in the modern world and should be sought in the follow-up study.

Some women spoke of learning how to manage relationships, avoid trouble (like being hi-jacked), and do business from the soaps:

I watch Generations and Isidingo and then news.... From Generations I learn doing business as woman. One day, God willing and if he keeps me safe under his arm, I will too do business like that one.

On the whole, individual respondents were not forthcoming when invited to talk about the programs they watched. Group discussions evoked more animated discussions than the dialogues, and the students at Maphephetheni were perhaps the most articulate. The group participating in the discussion at Cekeza was large, consisting of 28 men and women, but not all owned radios or televisions and thus were commenting on hearsay or infrequent listenership. The women interviewed thought they had learned from television but most were hesitant to say what. The groups were more forthcoming but responded in general terms. There were very few people who ventured any programs they didn't enjoy.

\section{Question 3}

Which radio programs do you listen to, which do you like most and least, and what do you learn from them?

The notion of materially poor but worthy people carving out a quiet and wholesome living for themselves in fertile lands of their birth is part of pastoral myth in South Africa. People may still be materially poor and worthy, but the land is not fertile and the air not quiet. From a lack of water and sanitation, through too little food and multiple diseases, the living is far from wholesome. With the advent of radio, life is not quiet either.

Of the 20 Maphephetheni households interviewed, 18 had radios-most of which were constantly turned on. Respondents did not necessarily listen to the radios but used them as background noise. Several people (six) said they didn't listen to anything, though the radio was on all the time, and two of these said it was because they were too tired:

\section{I listen to nothing because I am always at work and when I come home I do my housework and can't listen.}

Three recounted that they listened to everything:

Funerals, news, and the education programs; I listen throughout the whole day.

The radio program mentioned most often was the news, but it still was only mentioned five times in comparison with the 16 television news watchers. Also mentioned were music programs (three), stories (three), funeral notices (three) and women's programs (four).

At Cekeza the patterns of listenership were much the same: Thursday's women's program, news, stories, and notices being the most popular. Two of these are worth explaining, because from informal interaction and discussion these programs seemed to play a more integral part in people's lives than the interviews recorded. 
The women's Christian program was well received. Many people listened to it and several women talked about learning to manage their problems in a Christian way from it. One of these was the woman who earlier complained that one of the hardest things in her life was not being allowed to work by her husband. The conservative values preached by the program encouraged obedience to husbands and the fulfilment of women as mothers. There was no time to explore this lived contradiction.

I only listen to the women's program on Thursday during the day to learn the Christian way of being a good marriage and wife and also listen to the news, specially the top issues of the week.

I listen to the women's session on Thursdays, church songs, morning session radio Zulu; they usually have some [advice] given to people.

The funeral notices and a list of missing people are read every Thursday evening at nine o'clock. This public service program was started many years ago in direct response to the inability of migrant workers to communicate with those who had been left behind and vice versa. Migrants going to the city to look for work without an address or phone number could not be traced, and similarly since there were no phones and irregular postal services to rural areas it was often difficult for them to keep in touch with their rural families. "The Notices," as it is known, offers a service by reading names of missing people and the list of funerals. This is often the only way families get to hear of the death of kin. In 1998 this program still serves a valuable role:

I like the news and also the funeral notices although they are late but I always try to get them to know who's dead and who's alive.

\section{Question 4}

Is there enough light for you to read? Where do you read?

Homesteads in Maphephetheni and Cekeza follow the traditional pattern and consist of several separate buildings, usually rondavels (round mud huts) with thatch or, more commonly at Maphephetheni, corrugated iron roofs. Each hut has a particular function: a cooking hut in which a fire burns almost all the time, a dining hut in which most of the socializing happens, and, depending on the size of the household, a number of sleeping huts. The solar home system provides two or three lights, enough for the dining room, the main bedroom, and one outside light. Seventeen of the 20 households reported using candles in the other huts:

The dining room, verandah, [and] main-bedroom use solar; four rondavels use candles. The church building, which is in the yard, uses candles.

Thus, reading by solar light would have to be done in one of the three places. On the other hand, Eskom had electrified the entire homesteads so that all the rooms in all 17 homesteads in Cekeza had electric lights. This meant that there were none of the problems with too few lights that were reported in Maphephetheni or the problems with a lack of wiring that was reported in the urban study (Mehlwana and Qase 1997). Residents in Cekeza were entirely satisfied with their lighting and used all of the electric lights every night. This level of customer satisfaction must be gratifying to the utility and worth repeating:

In all my rooms there is electricity and I am happy that it is so. 
There is electricity everywhere, even in the outside bedrooms and bathroom, and it is safe and pleasant.

People who read were asked whether there was enough light for them to do so comfortably and whether they thought this was an important consideration. Overall good lighting was thought to be an advantage but it was especially important for school children. All those interviewed were pleased with the power of solar lighting for reading.

Yes, surely it's a lot better than it was before.

Those who had grid electricity were also completely satisfied, and those who used paraffin lamps said they put two lamps together to make enough light to read by.

\section{Question 5}

Who in the household likes to read? What do they read and how often?

Reading is acknowledged as important social skill, even (or perhaps especially) in the computer age. The week of September 7, 1998, was Literacy Week in South Africa. This was a week in which aliterate people (those who can read but don't) were encouraged to read and those who can't or have just learned how to read were encouraged to practice their skills. Thus, it was appropriate for us to be asking about reading at this time.

Illiteracy rates in rural areas of KwaZulu-Natal are reputedly as high as $80 \%$. The relatively high number of literate people who read regularly in Maphephetheni is a reminder that those with solar home systems were better off and closer to an urban area than those at Cekeza.

At Maphephetheni, 18 of the 20 households reported at least one member of the household who read regularly. These varied:

There's only one person who reads the Bible.

We read bibles, magazines, newspapers, etc. We read almost everything-Ilanga, Umafrika, Bona, Drum, Pace, whatever there is.

Seven of the 18 reading households mentioned the children in the household reading and seven mentioned the Bible as the primary reading material. The latter is probably read in Zulu, but other reading is done in Zulu and English. The most commonly read newspapers were Ilanga and Umafrika, both Zulu-language publications, and Pace, Bona, Drum, and Tribute magazines, the first two of which are published in Zulu and English. The only books being read, apart from the Bible, were schoolbooks. Parents rarely knew what subject matter these covered.

At Cekeza we recorded a relatively low number of readers. Eleven households reported that they read regularly, although in three of these it would appear to be only the children who read. Nine said they didn't read and four pointed out that the children were too young to read (and by implication that they couldn't). This low reading rate, coupled with the low number of radios and televisions, should have meant that the community had relatively little contact with the outside world. But as was evident in the previous question, the school teachers at least were involved and up to date with current affairs. 


\section{Question 6}

Do the children do homework?

In comparison with some areas of South Africa, both sites had well-functioning schools with dedicated staff. At each school there was some scarce equipment: in 1997 Myeka High received 20 IBM computers (although only 10 at a time work on solar) and Cekeza acquired a photocopier at the beginning of 1998. Dedicated staff are probably the most important ingredient in successful schooling, but these teachers' and students' resources cannot be compared with schools that have grounds with grass and trees and sporting facilities, comfortable classrooms with ceilings, glass windows, equipped laboratories, libraries, water, toilets, textbooks, overhead projectors, and audiovisual aids. A completely different level of schooling operates in urban and rural or rich and poor areas. What children do at school and should do at home has just as much variation.

At Maphephetheni, parents in eight households believed that their children did their homework regularly (every day or every second day) and nine said their children did homework "sometimes"about once a week. Most children did their homework at night and used the solar lighting to do so, some parents oversaw their work even when they themselves were illiterate:

Yes, at night, every day, they do their work, but I don't know what because I just see them writing every night.

Yes, they do their homework. They have to if they want to pass their studies. I always ensure that they do it ... because I don't want them to be like me.

At Cekeza, children did homework regularly in eight households, in four households parents said their children were too young, and in eight households the children did not do homework. Parents were critical of this lack of homework and there was some feeling that even children who did do homework did not do it diligently enough. Given the enthusiastic and involved teachers this is curious. There was not time to probe it or find out whether the pupils felt the same.

\section{Question 7}

Do the community hall, school, clinic, or shops use electricity at night?

There did not appear to be any communal energy use in the evenings at Maphephetheni. Although the courthouse has a solar system, it is not used at night. The other communal buildings, the development forum building and the clinics, are not wired. The school uses their solar power for the computers during the day.

At Cekeza, the school where the teachers stayed (Ecekeza High) was electrified, as was the Phola Phola store and the courthouse. The store used electricity at night, and an innovation this year has been to allow the students in their last year of school (matriculation) to study in a classroom at night. The security guard sees to the lights and security.

\section{Question 8}

Are there any adult education /literacy / extension classes?

This question was asked to find out whether electricity had impacted the quality of life of rural people through skills improvement. We also wanted to find out if people were taking advantage of these 
opportunities: whether "second chance" learning is being offered to adult learners. ${ }^{7}$ At Maphephetheni, the supply of solar systems has been to homesteads, so no changes in evening energy-use patterns in communal areas were evident. There was some interest in classes:

They once tried them and it just stopped. They also had sewing classes; I would like to be taught but haven't joined.

Not that I've heard of literacy classes, but it would be a good thing if we'd have it [be]cause we'd all be learned people.

The Inkosi was keen to start these kind of classes:

No, we don't have, but we want to start them soon. Together, I [will] work hand in hand with Myeka High School to do this.

At Cekeza there were no literacy classes, but there were other active social groups such as gardening, block making, and sewing. These were all organized and maintained informally and were non-profit making.

\section{Question 9}

What do you know about solar or PV power?

At Maphephetheni all respondents owned solar home systems and had a reasonably good understanding of how they worked. At Cekeza only two people had heard about solar, but many, especially the geography teacher, were curious to know more.

\section{Question 10}

Do you think solar electricity is/ would be enough electricity for you?

Eleven out of the 20 owners at Maphephetheni said that solar was not enough and nine said it was enough. Several qualified their responses:

No, because solar has limited power, you cannot cook or iron with it.

It's just enough because there's nothing else.

No, solar's not enough, but for the mean time, just temporarily before we have the Eskom lights, it'll do.

One replied on a happier note:

Solar's just enough; there's nothing that beats lighting up.

Not being able to use solar for cooking was a major complaint:

Nothing has changed because we are still collecting wood.

\footnotetext{
7 This is not to imply that this is a priority; indeed, the fatigue described by many women may preclude them from most non-essential activity outside of the homestead.
} 
We need electricity to cook with.

The respondents at Cekeza felt unable to commit themselves to an opinion without a better understanding of solar and seeing how it worked.

\section{Question 11}

What problems do you have with your electricity supply?

At Maphephetheni the solar home systems seem relatively robust; the primary complaint was again that it can't be used for cooking (eight respondents), there were no lights if it rained (four), and that they sometimes used up their supply before they were ready to go to bed (two). Six had no problems. Apart from mentioning the card "running out" and having to replace light bulbs, there were no problems with the electricity supply at Cekeza.

\section{Further Description and Analysis}

The pressures of this scoping study do not allow full reporting or analysis of group discussions. These were held to augment the conversations with individuals reported above. A couple of insights pertinent to the study are raised here, but further description and analysis should be done.

There were about 20 men (including the Inkosis) who participated either in the interviews or group discussions and who believed that the issues under deliberation were, directly or indirectly, pertinent to them. A recurring theme in the study was the incidence of unemployment, and all the men named it as the hardest parts of their lives. This has implications in terms of self-worth and identity (Campbell 1989) and also for households in terms of the affordability of alternatives to collecting wood.

At the first meeting with the women teachers at Ecekeza High School a teacher asked why men were not included in the group. We explained that experience had shown that women tended to be quiet in the presence of men and leave the talking to them. Since we were seeking women's opinions specifically, a meeting of only women had been arranged. However, men were not excluded from the interviews and were invited to the second meeting (and in fact there were almost equal numbers of men and women at the group meeting).

Asked why men should be included, women wanted the opportunity to reply with the following in front of men:

Men should pay the money for wood or electricity. Wood is a problem here, the forests are too far to walk to, although we are lucky in this area that the white farmers have forests and sometimes they let us collect a little bit, or sell to us. But sometimes if they catch you you're in trouble. We can't even afford electricity because the men haven't got jobs and just sit around.

At Cekeza there were vegetable gardens, a sewing group, and a block-making group-remnants, but nonetheless sustainable remnants - of projects that had been set up in the area by outside NGOs and which the women had carried on. The women said that none of these social groups (as they called them) made a profit; any income they received they ploughed back into the enterprises. In the beginning, men had participated in block making, but once the NGO people had left and there was no income forthcoming, the men "ran away." Only the women continue with the activities, which they say are doing good in the community even if they don't earn and income- they are hopeful that one day they will earn income. The women are, however, a little resentful that unemployed men sit 
around all day while they work endlessly. Asked why they did not participate, the men simply shrugged and said they couldn't work for no pay.

Much has been said and written about the limitations of analyzing gender in terms of roles. Current thinking emphasizes the need to go beyond the description of roles that men and women play (men as providers, women as caretakers) to analyze power relations that enable them to play these roles. We need to know what is it about male/female power relations that enables (in this case unemployed) men to decline labor while women continue to insist that it is the responsibility of men to provide money so that women can buy wood or electricity to cook.

Clearly, structural positions and physical force (domestic violence) play a part in maintaining the power relations. Culture and roles prevalent include the ideas that "gardening is not men's work"even though there are male farmers and men gardening in urban areas and "sewing is women's work"- even though most tailors are still men. Block making also becomes women's work when it does not earn a profit.

Notions of appropriate male/female behavior are changing, as is evident from the households in which men assist with domestic chores. A question is always whether outside agencies, such as energy experts, should promote these changes in gender relations (encourage men to collect wood) or provide an amelioration for women, such as fuel-efficient stoves, which may endorse roles and perpetuate aspects of the power relationship.

The women's group also asked who had done the planning for electrification (Eskom), whether it had been mostly men (yes), and why the planning and electrification was done before they were asked for input. Wouldn't it have been better, they asked, to have come to ask them first- then the right people or all the people could have electricity. As it is, all the people within the arbitrary boundaries on a map got electricity, whether they could afford it or not, and others who could afford it did not. This is a problematic consequence of extending the grid and saturating one area while not reaching adjacent homesteads. EDRC has raised this issue previously, and Eskom is aware of it.

The group of secondary school pupils from Maphephetheni gave lively input into the discussion on electrification-which they thought was essential for their jobs and the future. They were enthusiastic about school computers but frustrated because only about 10 pupils at a time could work off the system since there had not been money to by gas for the back-up system all term. Their understanding of what they were doing in the mathematics program (functions of $\mathrm{x}$ ) was minimal, but almost all had worked out how to get the 'right' answers. Cawood had organized that a visiting teacher would go to the school and assist the pupils further. Students thought electricity for a laboratory, welding workshop, and domestic science studio would provide opportunities for career training, which was otherwise unavailable to them. The headmaster, Mr. Zwane, had also introduced innovative curricula for tourism and travel, but they needed electricity to make these successful, too.

As far as non-formal learning went, the students said they learned from each other, their parents, their teachers, and also from television. Their interests were typical of trendy teenagers and their viewing included soccer (many had ambitions of representing South Africa) and a locally made soap opera, "Generations," which they watched to learn correct English pronunciation and language. It would be interesting to know whether English-speaking teenagers are watching Zulu language programs for the same reason. 


\section{Conclusion}

The non-economic determinants of energy use in rural areas was examined through two specific lenses, both of which reflect values and behaviors manifest in lifestyle, culture, convenience, habits, constraints, customs, preferences, priorities, control over, and access to resources. The lenses were the energy-use practices that impact the quality of women's lives and the energy-use practices in nonformal education.

It is clear that energy-related matters, in particular wood collection and the inability to pay for alternatives because of unemployment and chronic illness, contribute to the hardships in rural women's lives. Electrification delivers real, albeit sometimes intangible, benefits to women. This is the case with off-grid and on-grid electricity, although owners of solar home systems are less satisfied with their purchase than those who are grid connected. In both cases, (on grid and off grid) most households in the sample were too poor to take advantage of other fuels for cooking - which means that the arduous task of wood collection remains the bane of many women's lives.

The real issue highlighted by this further collection of data on multiple fuel use is the question, "Do I have to collect wood today?" The onus on older women, who are among those who complain of never being able to rest, is particularly heavy. The bitter irony is that they raised and educated their children at great personal cost in anticipation of being looked after in their old age. Instead, they are physically and financially (via their pensions) looking after their children's children and rest escapes them.

Where off-grid electrification offers little hope of alleviating the woodfuel burden, women at the gridelectrified site indicated that they were the primary beneficiaries of electricity because their workload could be reduced, if not immediately then over time. They demonstrated significant optimism about owning stoves "one day." The rate of appliance acquisition over 7 months in Cekeza (17 appliances in 20 households) would support this possibility. While current uptake may be low it would appear that low-income households anticipate increasing their energy use over time, and that energy-use patterns will alter as they use more electricity and less of other fuels-provided income supports this.

There is, however, a practical problem, which needs to be addressed. "Mini kitchens" (small plug-in, two-plate stoves with an oven costing R600/\$100) and "hotplates" (plug-in, twin-spiral or solid plates costing R100/\$16) are not designed for extended, heavy use. Women are using these appliances to cook staples for six to eight people, three hours a day, 365 days a year for many years. These stoves are designed for light use only, but appropriate stoves are beyond the pocket of rural buyers. A suitable appliance at an appropriate price should not be beyond the design capabilities of a country with nuclear capacity.

At Maphephetheni, satisfaction with improved lighting and safety was tempered by reservations that the electricity was not enough - that candles were still used and that thermal applications would have to wait for the grid or solar cookers. However, users showed sufficient faith in the value of the system to purchase it. Word-of-mouth, advertising, and demonstrations have produced a slow but steady growth in sales of off-grid systems. On the whole, people at both sites agreed that electrification offered an improvement in safety and security since fewer candles were used and there was less risk of losing possessions through fire. At the off-grid site, children were thought to be the primary beneficiaries of good lighting and television.

In terms of electricity providing the possibility of extending the day and facilitating income generation, most respondents reported not getting up at any different time, but pointed out that having electric lights made it easy to get up early if they wished to. About half the respondents at both sites 
did not think that electricity had lengthened their working hours at in the evening. The other half reported changed evening activities (such as watching television), and 11 women at Cekeza said that although they did not use the extended days for income generation at present they did not rule out the possibility of doing so in the future. Nine micro-enterprises, which may be income generating, were reported; seven of these were at the grid site. This is a relatively encouraging finding and bears further investigation as to how it can be supported and increased.

It is important that the electrification program be continued and extended to all homesteads within a set time period so that people know how long they have to wait. People in Maphephethini were distinctly unhappy that the area was not going to be electrified when the neighbors in the adjacent area had been. This issue is bound to be politicized in the coming elections. The Inkosi was particularly angry that there was no mechanism within Eskom for receiving part-payment from the community. The Development Forum had set aside over a million rand of their Reconstruction and Development Program (RDP) funds towards electrification, but Eskom had no structure to engage in negotiations to use this. This is not an uncommon finding (van Gass 1998). In the light of the RDP philosophy of enabling communities to help themselves, Eskom needs to address this request and provide a channel whereby co-payment for electrification is encouraged rather than ignored.

In Cekeza, there was a great deal of anger and frustration about those "not on the map" and not electrified, although the Inkosi's homestead, which was several kilometers from the spine, had been. More facilitative structures within Eskom are needed to keep people informed as to the real reason for non-electrification: the cost of infrastructure and non-recovery of capital costs. These concepts are not too difficult for people to understand and make more sense than the current explanation: being outside the surveyor's view.

There were strong opinions on egalitarianism within the community and that all households should be included in the benefits of electrification. In group discussion at Cekeza, Maria Mbuli played the role of a very poor person going to an Eskom official to ask for electricity. In her role, she explained that she couldn't afford a pre-payment card but that her rondavel was cold and dark and she was largely bedridden. She pleaded for light, just one light—what should she do? The person playing the Eskom official declined to help her, explaining why he could not, but the community took up her issue and said that they were prepared to make a substantial contribution to her electricity every month. Role play does not, of course, always translate into action, but it will be interesting to see whether on the return visit any such arrangements have been made for very poor people. ${ }^{8}$

Future policy should consider street lighting, which clearly contributes significantly to men and women's safety ${ }^{9}$ and security. Street lighting might be one of the areas in which renewables may most cost-effectively be used. The experience in Richmond of the contribution of mast lights to decreasing crime should be noted and an appropriate policy developed. The Energy and Development Research Centre could play an effective role in thinking through and developing such a policy. Maphephethni may be an ideal site to pilot solar mast lights.

We observed few wasteful practices in fuel use. We suggested chimneys or roof openings to provide immediate relief from excessive wood smoke. A return visit will show whether the suggestion was considered worthwhile. As wood scarcity increases, efficient stoves and /or solar cookers may be

\footnotetext{
${ }^{8}$ The National Electricity Regulator has proposed a poverty tariff to be administered by Eskom and introduced in 1999. This is currently being debated.

${ }^{9}$ A women gets raped every 87 seconds in South Africa: Geraldine Fraser Moleketi, June 12, 1998 .
} 
more acceptable and offer short-term relief to wood collection, but neither are likely to provide a longer-term solution.

Wicks on paraffin stoves need to be kept trimmed to prevent excessive fumes, which was also suggested, as was using the minimum flame possible on paraffin and gas stoves. There was some misunderstanding about the heat settings (1-3) on electric plates, which should be addressed at the point of sale, so that heat is reduced as soon as food comes to the boil. An extremely helpful comparative demonstration would be to cook a staple food simultaneously in a solar cooker, on gas, on paraffin, and on an electric stove. That way, prepayment cards and paraffin could be efficiently measured and the gas weighed and calculated.

The problem of having to cook at mid-day with solar may be overcome within communities. In any case, the solution to the need for energy for thermal applications will be linked to affordability-this is the root problem that must be addressed.

Education about energy use and conservation were minimal at Cekeza. At Maphephetheni, the solar home systems were relatively well understood. The teachers at both sites were willing and able to learn and pass on such information and appeared to enjoy the interaction with the researchers. They are useful conduits for getting information into the community rapidly.

Non-formal education benefits from electrification in that good lighting is used by about $60 \%$ of households, children in particular, for reading. Reading material, however, is scarce. Neither site has access to even a school library or reading room. Good light is likely to be better for eyesight, too.

The news was the most popular program on radio and television. People reported that they learned about different cultures and places, heard stories about what was going on throughout the whole world, listened to sessions in parliament, and saw and heard many new (unspecified) things. The Non Aligned Movement summit being held in Durban and the first anniversary of Princess Di's death were current events that raised much interest.

Prime viewing time is important for messages that need to be heard by the nation. For example, Deputy President Thabo Mbeki's address on HIV-AIDS may have been heard by more people if it had been carried on the main evening news bulletins rather than at mid-day.

The section of this study on the non-economic benefits of electrification for non-formal education is too large and important to be linked with that on the quality of life of women. The interviews tended to take too long; participants lost focus and concentration. This part of the study needs a different methodology where character recognition and identification, among other things, can be explored and conscious and inadvertent learning investigated more thoroughly and systematically through dialogue and discussion.

Discussions at both sites confirm the importance of electricity for education. Lights for homework and electricity at schools were perceived as important factors in improved living conditions, and the general trend was towards optimism for the future. However, it was especially noticeable at Cekeza that people's assessment of the likelihood of improved lives for the children was tempered by their experience of a lack of employment opportunities.

\section{Economic Determinants of Rural Life}

It is clear that energy policy makers will have to monitor the impact of the electrification program and multiple fuel use in a systematic and on-going manner, in conjunction with the macro-economic 
conditions. It has been recognized that the world economic order is changing, that the current Growth Employment and Redistribution (GEAR) strategies are not meeting the needs of the unemployed and the poor (Alec Erwin, Minister DTI Safm 19.10.98), and that creative thinking will be needed to find new solutions. A contribution to this will be the Job Summit held at the end of October 1998.

Although the focus of this report is non-economic determinants of energy use, it would be irresponsible to neglect to mention the importance of the financial constraints of the group of users under investigation. Significant benefits to the entire household, including establishing microenterprises and better use of electricity, could be achieved if just one adult per household received a regular income of R500 per month $(\$ 80)$. This is significantly below the minimum wage. It is in no way suggested as an alternative full-time wage but simply as an indicator of what a difference a relatively small income could make to each household. It is already evidenced by the relative stability of those households receiving a state pension or disability grant. Such a grant is not be beyond the capabilities of this country (Baskin 1998).

There is probably a level of income at which the non-economic determinants contribute significantly to determining choice and therefore energy-use patterns. Choice is more possible where income, education, and availability are high than where existence itself is marginal. A lifestyle that includes such choice is currently substantially beyond the income of most rural energy users. Economics is determinant in the first and last instance (with apologies to Althuser).

The findings of this study may be disappointing to protagonists of solar home systems and renewables in general. Certainly, follow-up work is necessary to confirm the findings. Commercial, viable solar homes systems may also find favor in urban areas where local governments are unable to electrify large tracts of informal settlements because tenure has not been granted. It would appear that these sites, which are more accessible for installation and maintenance, might be ideal grounds to build capacity and increase markets.

The single important point to make is that, in 1998, it is not acceptable for a third of the women in South Africa to be collecting and carrying wood twice a week for 7 or 8 hours at a stretch. There is little point in having a constitution enshrining human and equal rights, a gender commission, or colorful advertisements on television that "salute the women of Africa" when what the women want is not accolades and promissory notes but to be relieved of having to carry water and wood in the new millennium. 


\section{References}

Annecke, W.J. 1993. An in-depth investigation into fuel use by urban women. Report for the Department of Mineral and Energy Affairs. Pretoria.

Banks, D.I. 1996. Solar home systems: techno-economic study. Annex 4 - 13. Rondebosch: Energy and Development Research Centre.

Banks, D.I. 1998. Off-grid electrification for the poor: constraints and possibilities. Draft final paper. Rondebosch: Energy and Development Research Centre.

Baskin, J. 1998. A basic income for South Africa. Business Day. 28.04.98.

Cawood, W.N. 1997. Maphephethe non-grid SHS rural electrification programme, Phase 2. Final report prepared for the Department of Minerals and Energy.

Crawford-Cousins, C. 1998. A question of power: electrification of rural households. Energy and Development Research Centre, University of Cape Town.

Davis, M. 1995. Insitutional frameworks for electricity supply to rural communities: A literature review. Energy and Development Research Centre, University of Cape Town.

Green, J.M. and S.H. Erskine. 1998. An energy audit of Maphephethe: Assessing present energy usage patterns as a precursor to the introduction and expansion of alternative energy resources.

Pietermartizburg: University of Natal.

James, B. 1996. Exploring the silences. Energy and Development Research Centre, University of Cape Town.

May, J. 1998. (ed). Poverty and Inequality in South Africa, Report prepared for the Office of the Executive Deputy President and the Inter-Ministerial Committee for Poverty and Inequality, Praxis Publishing, Durban.

Morgenstern, J. 1997. Renewable Energy for Rural Electrification in Developing Countries: The Impact of Appropriate Energy Technologies. Field Study Report.

Van Gass, M. 1998. The problematics of electrification programmes in rural KwaZulu-Natal. Energy and Development Research Centre, University of Cape Town. 


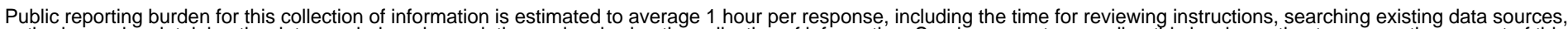

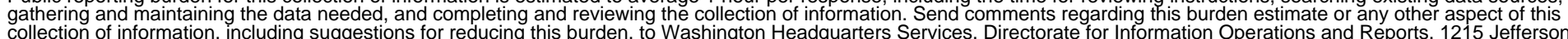
Davis Highway, Suite 1204, Arlington, VA 22202-4302, and to the Office of Management and Budget, Paperwork Reduction Project (0704-0188), Washington, DC 20503.
1. AGENCY USE ONLY (Leave blank)
2. REPORT DATE
3. REPORT TYPE AND DATES COVERED
February 1999
Subcontractor Report

4. TITLE AND SUBTITLE

Non-Economic Determinants of Energy Use in Rural Areas of South Africa

5. FUNDING NUMBERS

PV90.9007

6. $\operatorname{AUTHOR}(\mathrm{S})$

Wendy Annecke, Energy and Development Research Center, University of Cape Town South Africa

7. PERFORMING ORGANIZATION NAME(S) AND ADDRESS(ES)

8. PERFORMING ORGANIZATION REPORT NUMBER

National Renewable Energy Laboratory

1617 Cole Boulevard

SR-620-25868

Golden, Colorado 80401-3393

9. SPONSORING/MONITORING AGENCY NAME(S) AND ADDRESS(ES)

10. SPONSORING/MONITORING AGENCY REPORT NUMBER

U.S. Department of Energy

1000 Independence Ave., SW

Washington, DC 20585

11. SUPPLEMENTARY NOTES

12a. DISTRIBUTION/AVAILABILITY STATEMENT

National Technical Information Service

U.S. Department of Commerce

5285 Port Royal Road

Springfield, VA 22161 12b. DISTRIBUTION CODE

13. ABSTRACT (Maximum 200 words)

This project will begin to determine the forces and dimensions in rural energy-use patterns and begin to address policy and implementation needs for the future. This entails:

- Forecasting the social and economic benefits that electrification is assumed to deliver regarding education and women's lives

- Assessing negative perceptions of users, which have been established through the slow uptake of electricity

- Making recommendations as to how these perceptions could be addressed in policy development and in the continuing electrification program

- Making recommendations to policy makers on how to support and make optimal use of current energy-use practices where these are socio-economically sound

- Identifying misinformation and wasteful practices

- Other recommendations, which will significantly improve the success of the rural electrification program in a socio-economically sound manner, as identified in the course of the work

14. SUBJECT TERMS

South Africa, energy, non-economic determinants of, rural energy use
15. NUMBER OF PAGES

51

16. PRICE CODE

20. LIMITATION OF ABSTRACT

UL
OF REPORT

unclassified
18. SECURITY CLASSIFICATION OF THIS PAGE

Unclassified
19. SECURITY CLASSIFICATION OF ABSTRACT unclassified 